\title{
An Improved Canopy Integration Scheme for a Land Surface Model with Prognostic Canopy Structure
}

\author{
PETER E. THORNTON \\ Climate and Global Dynamics Division, National Center for Atmospheric Research,* Boulder, Colorado \\ NiKLAUS E. ZiMMERMANN \\ Department of Landscape Research, Swiss Federal Research Institute WSL, Birmensdorf, Switzerland
}

(Manuscript received 15 November 2005, in final form 17 October 2006)

\begin{abstract}
A new logical framework relating the structural and functional characteristics of a vegetation canopy is presented, based on the hypothesis that the ratio of leaf area to leaf mass (specific leaf area) varies linearly with overlying leaf area index within the canopy. Measurements of vertical gradients in specific leaf area and leaf carbon:nitrogen ratio for five species (two deciduous and three evergreen) in a temperate climate support this hypothesis. This new logic is combined with a two-leaf (sunlit and shaded) canopy model to arrive at a new canopy integration scheme for use in the land surface component of a climate system model. An inconsistency in the released model radiation code is identified and corrected. Also introduced here is a prognostic canopy model with coupled carbon and nitrogen cycle dynamics. The new scheme is implemented within the Community Land Model and tested in both diagnostic and prognostic canopy modes. The new scheme increases global gross primary production by $66 \%$ (from 65 to $108 \mathrm{Pg}$ carbon $\mathrm{yr}^{-1}$ ) for diagnostic model simulations driven with reanalysis surface weather, with similar results $\left(117 \mathrm{PgC} \mathrm{yr}^{-1}\right)$ for the new prognostic model. Comparison of model predictions to global syntheses of observations shows generally good agreement for net primary productivity (NPP) across a range of vegetation types, with likely underestimation of NPP in tundra and larch communities. Vegetation carbon stocks are higher than observed in forest systems, but the ranking of stocks by vegetation type is accurately captured.
\end{abstract}

\section{Introduction}

Numerical models of the global climate system typically include a component submodel that treats the dynamics of energy and mass exchange at the land surface (Xue et al. 1991; Ducoudré et al. 1993; Mahfouf et al. 1995; Johns et al. 1997; Bonan 1998; Cox et al. 1999; Berthelot et al. 2002; Delworth et al. 2002; Dickinson et al. 2006). The various land surface component models are similar in many respects, since each must serve as a physically reasonable lower boundary responding to and constraining atmospheric fluxes of energy, mois-

\footnotetext{
* The National Center for Atmospheric Research is sponsored by the National Science Foundation.
}

Corresponding author address: Peter E. Thornton, Climate and Global Dynamics Division, National Center for Atmospheric Research, 1850 Table Mesa Dr., Boulder, CO 80503.

E-mail: thornton@ucar.edu ture, and, in many cases, carbon. In particular, some representation of the physical and biophysical properties of the vegetation canopy is a common feature in many land surface component models. Such canopy models employ, at least implicitly, logic that relates process information and fluxes at the leaf level to integrated fluxes at the canopy level (Dickinson 1984; Sellers et al. 1986, 1992).

Recent developments in coupled climate system modeling have produced a dichotomy among land surface models based on their treatment of the structure of vegetation canopies as either diagnostic or prognostic. Diagnostic canopy models represent vegetation canopies as static or temporally cyclic boundary conditions, usually constrained by remote sensing interpretations of quantities such as leaf area index (e.g., Boone et al. 2004; Dickinson et al. 2006). Prognostic canopy models represent at least some aspect of the vegetation structure through predictive state variables, such as leaf or stem carbon pools, which are coupled to model fluxes,

DOI: $10.1175 /$ JCLI4222.1 
a)

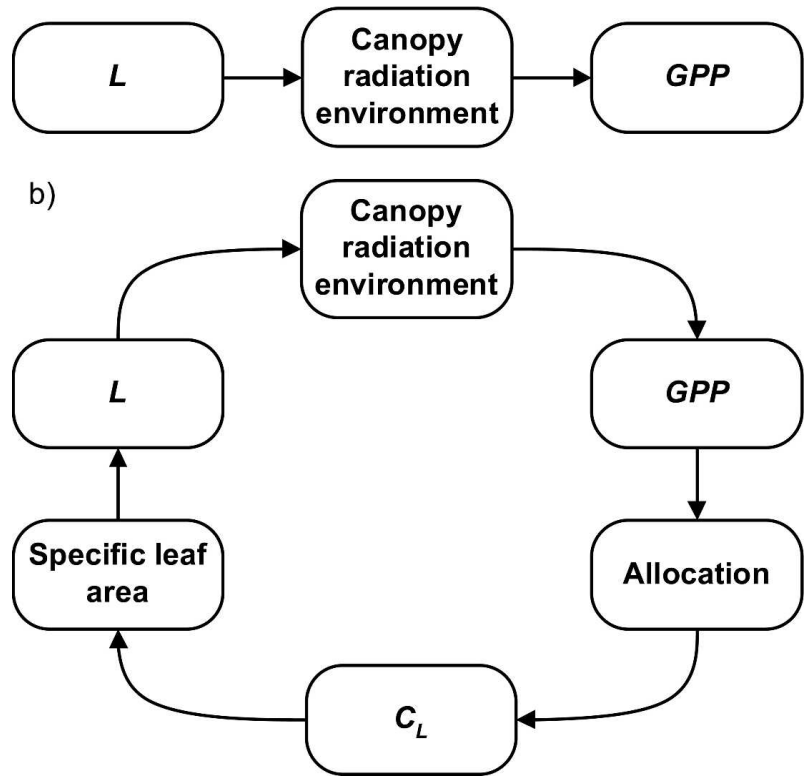

FIG. 1. Schematic showing the dependencies between canopy leaf area index $(L)$, the canopy radiation environment, and GPP for idealized (a) diagnostic and (b) prognostic canopy models, where (b) also illustrates the prognostic model feedback between GPP and $L$ acting through allocation to leaf carbon $\left(C_{L}\right)$ and SLA.

such as photosynthetic carbon uptake or emissions from fire (e.g., Betts et al. 1997; Dickinson et al. 1998; Cox et al. 2000; Levis et al. 2000; Friedlingstein et al. 2001; Dickinson et al. 2002; Dufresne et al. 2002; Delire et al. 2004).

In a diagnostic model there is generally a simple, direct relationship between canopy leaf area index $(L$; $\mathrm{m}^{2}$ one-sided leaf area $\mathrm{m}^{-2}$ ground area) and gross primary production (GPP; $\mathrm{gC} \mathrm{m}^{-2} \mathrm{yr}^{-1}$; Fig. 1a). In a prognostic model this relationship takes the form of a feedback loop, with GPP depending on $L$ as in a diagnostic model, but also with the canopy-level pool of leaf carbon $\left(C_{L} ; \mathrm{gC} \mathrm{m}^{-2}\right)$ depending on GPP, and $L$ depending on $C_{L}$ (Fig. 1b). Specific leaf area (SLA; $\mathrm{m}^{2}$ one-sided leaf area $\mathrm{gC}^{-1}$ ), the ratio of leaf area to leaf mass, is a critical parameter in this feedback pathway, providing the structural parameterization that links $C_{L}$ to $L$, and participating in the biochemical parameterization of area-based photosynthetic enzyme concentrations linking $L$ to GPP (Reich et al. 1998).

A vertical gradient in SLA is reported for canopies of many different vegetation types, with thicker leaves (lower SLA) at the top of the canopy and thinner leaves (higher SLA) at the bottom, including studies in temperate deciduous forest (Hollinger 1996; Niinemets and
Tenhunen 1997; Niinemets and Kull 1998; Roberts et al. 1999; Cramer et al. 2000; Wilson et al. 2000; Meir et al. 2002), temperate evergreen forest (Monserud and Marshall 1999; Bond et al. 1999; Meir et al. 2002; Niinemets et al. 2002; Han et al. 2003; White and Scott 2006), boreal forest (Dang et al. 1997), tropical rain forest (Poorter et al. 1995; Ishida et al. 1999; Carswell et al. 2000; Souza and Válio 2003; Kumagai et al. 2006), and in relatively high leaf area $(L>2.0)$ grassland (Knops and Reinhart 2000), orchard (Le Roux et al. 1999; Rosati et al. 1999, 2000), and crops (Gutschick and Wiegel 1988). This variation is observed to be closely related to the light environment experienced during leaf development (Sims and Pearcy 1989; Hikosaka et al. 1994; Reich et al. 1995; Hollinger 1996; Poorter and Evans 1998; Meziane and Shipley 1999; Evans and Poorter 2001). Insignificant vertical gradient in SLA has been observed in grassland (Friedl et al. 1994) and savanna tree canopies (Scholes et al. 2004) with low leaf area $(L<2.0)$ and minimal self-shading.

This variability has important implications for both canopy structure and canopy function. Structurally, a vertical gradient in SLA means that the increment in $C_{L}$ producing a given increment in $L$ decreases with increasing $L$ (Gutschick and Wiegel 1988). Functionally, the gradient in SLA is commonly observed to be the dominant factor controlling vertical variation in area-based leaf nitrogen and photosynthetic rate, as there is typically little vertical variation in the massbased concentrations of nitrogen (Hollinger 1996; Niinemets and Kull 1998; Bond et al. 1999; Ishida et al. 1999; Le Roux et al. 1999; Roberts et al. 1999; Rosati et al. 2000; Carswell et al. 2000; Evans and Poorter 2001; Meir et al. 2002; Kumagai et al. 2006; White and Scott 2006) or in fractional partitioning of nitrogen to ribulose bis-phosphate carboxylase-oxygenase (Rubisco, the enzyme responsible for fixation of carbon dioxide in the chloroplast; Niinemets et al. 1998; Evans and Poorter 2001; Han et al. 2003).

The diagnostic canopy models generally ignore SLA altogether, since $L$ is prescribed and $C_{L}$ is not included as a prognostic variable. The prognostic models include SLA as a parameter, generally defined to vary among plant functional types (PFTs), but to date no prognostic canopy land surface component of a global climate model has explicitly included the observed vertical variability of SLA within the canopy. An analytical model of the relationship between $C_{L}, L$, and SLA in a canopy with vertical gradient in SLA is given by Gutschick and Wiegel (1988), and this variability is included in several stand-alone vegetation canopy models (Thornton 1998; Raulier et al. 1999; Thornton et al. 2002). 
Rather than treating the gradient in SLA explicitly, diagnostic and prognostic canopy models have typically assumed a declining area-based leaf nitrogen concentration $\left(N_{a}\right)$ with overlying leaf area index ( $x$; Reynolds et al. 1992; Sellers et al. 1992; de Pury and Farquhar 1997; Wang and Leuning 1998; Dickinson et al. 2002; Dai et al. 2004), defined in most cases as an exponential decrease in $N_{a}$ with $x$ that follows the canopy gradient in absorbed photosynthetically active radiation (APAR; Field 1983; Hirose and Werger 1994; Dewar 1996; Medlyn 1996). This formulation provides a functional link between leaf-scale concentration of Rubisco and canopy position, but it leaves unresolved the relationship between the vertical distributions of leaf carbon and leaf nitrogen.

Several studies have demonstrated that sunlit and shaded canopy fractions should be treated separately when scaling carbon and water fluxes from leaf to canopy to avoid large biases (Sinclair et al. 1976; Norman 1980; Reynolds et al. 1992; Stockle 1992; de Pury and Farquhar 1997). Several models combine this approach with analytical expressions of vertical canopy gradient in $N_{a}$ to obtain relatively simple and accurate scaling expressions for canopy fluxes in diagnostic (Reynolds et al. 1992; de Pury and Farquhar 1997; Wang and Leuning 1998; Dai et al. 2004) and prognostic (Delire et al. 2004) models. The current state-of-theart in canopy flux modeling both resolves the vertical gradients in photosynthetic capacity and treats at least two distinct classes of leaves, sunlit and shaded.

Here we present a new model that advances the state-of-the-art by introducing an explicit treatment of the vertical variation in SLA with $x$, joining the previous work on treatment of vertical gradients in photosynthetic capacity and sunlit/shaded canopy scaling with new prognostic equations relating $L$ and $C_{L}$, providing a consistent description of canopy structure and function. The new model is based on observables at the leaf scale and is applicable to both diagnostic and prognostic canopy models. The new model is implemented within the Community Land Model (CLM) component of the Community Climate System Model (CCSM; Dickinson et al. 2006; Collins et al. 2006), as part of an ongoing effort to add prognostic carbon and nitrogen cycling capabilities to CCSM.

The current released version of CLM (CLM3; Dickinson et al. 2006) employs an unusual canopy scaling approach, and requires some introduction here. CLM3 does not include treatment of the vertical gradient in photosynthetic capacity, having a single value of maximum carboxylation rate at $25^{\circ} \mathrm{C}\left(V_{\text {cmax,25 }}\right)$ for each plant functional type. Given a canopy leaf area $L$, CLM3 uses standard formulations to estimate the sunlit leaf area $\left(L_{\text {sun }}\right)$ and shaded leaf area $\left(L_{\text {sha }}=L-L_{\text {sun }}\right)$, as well as the fractions of downward direct and diffuse radiation absorbed in the canopy (following Dai et al. 2004). Instead of partitioning these absorbed fluxes to the sunlit and shaded canopy fractions, as described by Dai et al. (2004), the total absorbed flux from the direct and diffuse incident streams is instead assigned entirely to the sunlit canopy fraction, with zero flux assigned to the shaded canopy fraction (Oleson et al. 2004), so for water and carbon flux estimates CLM3 is structured as a variant of the single big leaf model (cf. de Pury and Farquhar 1997). Because of this treatment, APAR per unit leaf area in the sunlit (active) canopy under the CLM3 scheme is frequently in the light-saturated range for leaf-scale photosynthesis, with photosynthesis likely underestimated compared to more typical big-leaf models that distribute total canopy intercepted radiation over $L$ to obtain the leaf-scale incident radiation flux (Sellers et al. 1992).

In addition to this unusual, but intentional, implementation of the big-leaf model, we have identified an unintentional inconsistency in the CLM3 calculation of leaf-scale carbon fluxes. The PAR flux passed to the leaf-scale photosynthesis routine is intended to be the flux density per unit (sunlit) leaf area $\left(\mathrm{PAR}_{L}\right)$, but what is in fact passed is the total canopy absorbed PAR expressed per unit ground area $\left(\mathrm{PAR}_{C}\right)$. Since $\mathrm{PAR}_{L}=$ $\operatorname{PAR}_{C} / L_{\text {sun }}$, the result of this inconsistency is an underestimate of leaf-scale absorbed PAR for $L_{\text {sun }}<1.0$, and an overestimate of leaf-scale absorbed PAR for $L_{\text {sun }}>$ 1.0 (ignoring for the moment other biases associated with the unusual formulation of the CLM3 big-leaf model).

Below we present the details of our new canopy integration and scaling scheme, including changes in CLM3 to adopt a more standard two-big-leaf model for sunlit and shaded canopy fractions, and correction of the error in leaf-scale absorbed PAR. Details of the new prognostic canopy model are presented as necessary to the interpretation of results from global simulations. A central hypothesis of our model is that, at the species level, the vertical gradient in SLA can be represented as a linear function $\operatorname{SLA}(x)$ while the massbased leaf nitrogen concentration $\left(N_{m}\right)$ remains constant with $x$. We present new observations collected to test that hypothesis in temperate deciduous and evergreen forest stands in Switzerland. In a stepwise sensitivity analysis we demonstrate the behavior of the new model as implemented in CLM, using both diagnostic and prognostic canopy formulations. We also examine integrated model behavior through several global simulations forced by reanalysis surface weather fields. 


\section{Model description}

\section{a. Canopy vertical gradient in SLA}

Based on previous observations in multiple vegetation types (cited above), we assume that a linear relationship between SLA and $x$ holds for all types of plant canopies and specify that

$$
\operatorname{SLA}(x)=\operatorname{SLA}_{0}+m x,
$$

where $\mathrm{SLA}_{0}\left(\mathrm{~m}^{2}\right.$ one-sided leaf area $\left.\mathrm{gC}^{-1}\right)$ is a fixed value of SLA at the top of the canopy, $m$ is a linear slope coefficient, and $x$ is the canopy depth expressed as overlying leaf area index $\left(\mathrm{m}^{2}\right.$ overlying one-sided leaf area $\mathrm{m}^{-2}$ ground area). All variables and associated units are listed in the appendix (Table A1). Here, SLA S $_{0}$ and $m$ are both assumed to vary by species or plant functional type. Integrating over the canopy gives total canopy leaf carbon $C_{L}\left(\mathrm{gC} \mathrm{m}^{-2}\right.$ ground area $)$ as

$$
C_{L}=\int_{0}^{L} \frac{1}{\operatorname{SLA}(x)} d x=\frac{\ln \left[\left(m L+\mathrm{SLA}_{0}\right)-\ln \left(\mathrm{SLA}_{0}\right)\right]}{m},
$$

which can be rearranged to solve for $L$ when $C_{L}$ is given as a model prognostic variable

$$
L=\frac{\operatorname{SLA}_{0}\left[\exp \left(m C_{L}\right)-1\right]}{m} .
$$

Note that for implementation in a diagnostic model Eq. (3) is not used, since $L$ is prescribed.

\section{b. Treatment of sunlit and shaded canopy fractions}

We use the formulation from Dai et al. (2004) to calculate the fractions of sunlit and shaded leaves $\left(f_{\text {sun }}\right.$ and $\left.f_{\text {sha }}\right)$ at canopy depth $x$ :

$$
f_{\text {sun }}(x)=e^{-k_{b} x} ; \quad f_{\text {sha }}=1-f_{\text {sun }},
$$

and the sunlit and shaded canopy leaf area $\left(L_{\text {sun }}\right.$ and $\left.L_{\text {sha }}\right)$ :

$$
L_{\mathrm{sun}}=\int_{0}^{L} f_{\mathrm{sun}}(x) d x=\frac{1-e^{-k_{b} L}}{k_{b}} ; \quad L_{\mathrm{sha}}=L-L_{\mathrm{sun}},
$$

where $k_{b}$ is the direct beam extinction coefficient of the canopy, which varies with the solar zenith angle and the leaf angle distribution (see Dai et al. 2004 for further details).
Rates of photosynthesis are calculated at the leaf scale (i.e., per unit leaf area) for both the sunlit and shaded canopy fractions using the model of Farquhar et al. (1980) and Farquhar and von Caemmerer (1982), implemented as described in Oleson et al. (2004), but using the corrected calculation of leaf-scale APAR for the sunlit and shaded fractions, following Dai et al. (2004). We also modify the treatment of leaf-scale maximum carboxylation capacity of Rubisco $\left(V_{\mathrm{cmax}}\right.$; umol $\left.\mathrm{CO}_{2} \mathrm{~m}^{-2} \mathrm{~s}^{-1}\right)$. Although prescribed as a constant for a given plant type in CLM3 (Oleson et al. 2004), $V_{\text {cmax }}$ is more realistically formulated as a dynamic quantity that depends on the leaf area-based concentration of Rubisco and the enzyme activity (Niinemets and Tenhunen 1997), as

$$
V_{\mathrm{cmax}}=N_{a} F_{\mathrm{LNR}} \frac{1}{F_{\mathrm{NR}}} a_{R},
$$

where $N_{a}$ is the area-based leaf nitrogen concentration ( $\mathrm{gN} \mathrm{m}{ }^{-2}$ one-sided leaf area), $F_{\mathrm{LNR}}$ is the fraction of leaf nitrogen in Rubisco (unitless), $F_{\mathrm{NR}}$ is the mass ratio of nitrogen in the Rubisco molecule to total molecular mass (unitless), and $a_{R}$ is the specific activity of Rubisco (umol $\mathrm{CO}_{2}$ gRubisco $^{-1} \mathrm{~s}^{-1}$ ).

Woodrow and Berry (1988) give an estimate of $a_{R}$ at $25^{\circ} \mathrm{C}$ and its temperature dependence, and we calculate $F_{\mathrm{NR}}$ as $\sim 0.14$ on the basis of protein subunit analyses of the enzyme (Kuehn and McFadden 1969). Here, $F_{\text {LNR }}$ can be estimated from leaf-scale gas exchange measurements, given the corresponding $N_{a}$ for the sampled leaves, and $N_{a}$ is related to specific leaf area and massbased leaf $N$ content as

$$
N_{a}=\frac{1}{\mathrm{SLA} \cdot \mathrm{CN}_{L}},
$$

where $\mathrm{CN}_{L}$ is the leaf carbon:nitrogen ratio $\left(\mathrm{gC} \mathrm{gN}^{-1}\right)$.

The variables $F_{\mathrm{NR}}$ and $a_{R}$ are assumed to be fundamental properties of the enzyme, and we treat them as constants for all plant types. Both $F_{\mathrm{LNR}}$ and $\mathrm{CN}_{L}$ are known to vary among plant types (Field et al. 1983; Wullschleger 1993), but, as cited above, there is evidence that they vary little with canopy depth for a given plant type. We therefore assume that most of the variation in $V_{\text {cmax }}$ with $x$ will result from variation in SLA, and we test that assumption in our canopy gradient measurements, described below.

The mean values of SLA in the sunlit and shaded canopy fractions, SLA $\mathrm{Sun}_{\text {sun }}$ and SLA $_{\text {sha }}$, are calculated as

$$
\operatorname{SLA}_{\text {sun }}=\frac{\int_{0}^{L} \operatorname{SLA}(x) f_{\text {sun }}(x) d x}{L_{\text {sun }}}=\frac{-\left(c_{1} m k_{b} L+c_{1} m+c_{1} \operatorname{SLA}_{0} k_{b}-m-\operatorname{SLA}_{0} k_{b}\right)}{k_{b}^{2} L_{\text {sun }}}
$$




$$
\operatorname{SLA}_{\text {sha }}=\frac{\int_{0}^{L} \operatorname{SLA}(x) f_{\text {sha }}(x) d x}{L_{\text {sha }}}=\frac{L\left(\operatorname{SLA}_{0}+\frac{m L}{2}\right)-\operatorname{SLA}_{\text {sun }} L_{\text {sun }}}{L_{\text {sha }}},
$$

where $c_{1}=\exp \left(-k_{b} L\right)$. The form for Eq. (8b) has been rearranged to take advantage of previous calculation of $\mathrm{SLA}_{\text {sun }}$. Because $k_{b}$ varies with solar zenith angle, $L_{\text {sun }}$, $L_{\text {sha }}, S_{\text {sun }}$, and SLA $_{\text {sha }}$ all exhibit diurnal and seasonal variation, with important consequences for canopy-scale calculation of GPP. Note that Eqs. (5)-(8) can be used to parameterize the photosynthesis calculations for both diagnostic and prognostic canopy models, depending only on a previous specification of $L$. Here, $N_{a}$ for the sunlit and shaded canopy fractions is given as

$$
\begin{aligned}
& N_{a, \text { sun }}=\frac{\int_{0}^{L} N_{a}(x) f_{\text {sun }}(x) d x}{L_{\text {sun }}} \\
& N_{a, \text { sha }}=\frac{\int_{0}^{L} N_{a}(x) f_{\text {sha }}(x) d x}{L_{\text {sha }}} .
\end{aligned}
$$

The integrals in Eq. (9) do not have analytical solutions. We test here the error introduced by using Eqs. (7) and (8) to estimate $N_{a \text {,sun }}$ and $N_{a \text {,sha }}$ for use in Eq. (6), compared to a numerical integration of Eq. (9) to calculate $N_{a \text {,sun }}$ and $N_{a \text {,sha }}$ directly.

\section{c. Allocation of carbon to leaves}

In the absence of nitrogen limitations (see below), allocation of carbon from primary production to various plant pools depends on GPP, instantaneous carbon demand for respiration to support existing live tissues [maintenance respiration, $R_{m}\left(\mathrm{gC} \mathrm{m}^{-2} \mathrm{~s}^{-1}\right)$ ], and on the specified relationships between allocation to new leaf carbon $\left(C_{\mathrm{La}}\right)$, new stem carbon $\left(C_{\mathrm{Sa}}\right)$, and new fine and coarse root carbon $\left(C_{\mathrm{FRa}}\right.$ and $C_{\mathrm{CRa}}$, respectively). The variable $C_{\mathrm{La}}$ is calculated as

$$
C_{\mathrm{La}}=\frac{\mathrm{GPP}-R_{m}}{(1+g)\left[1+a_{1}+a_{2}\left(1+a_{3}\right)\right]},
$$

where $g$ is the growth respiration cost per unit of newly allocated carbon, $a_{1}$ is the ratio of newly allocated $C_{\mathrm{FRa}}$ : $C_{\mathrm{La}}, a_{2}$ is the ratio of newly allocated $C_{\mathrm{Sa}}: C_{\mathrm{La}}$, and $a_{3}$ is the ratio of newly allocated $C_{\mathrm{CRa}}: C_{\mathrm{Sa}}$. For nonwoody vegetation, $a_{2}=a_{3}=0$. We note that this parameterization leaves out an explicit representation of stem carbon for nonwoody vegetation types, and that a better approach is especially desirable for crops. Of $C_{\mathrm{La}}$, a specified fraction is displayed immediately as new growth, and the remainder is stored for subsequent display, under the control of the model's phenology algorithms. The instantaneous value of $C_{L}$ is calculated as the time integral of carbon gains from new growth and transfers from storage, and losses due to litterfall and mortality, including fire. Additional details on allocation, phenology, and mortality algorithms are provided in Thornton (1998), Thornton et al. (2002), and Thornton and Rosenbloom (2005).

\section{d. Coupling between carbon and nitrogen cycles}

In addition to the novel canopy integration scheme described above, this study uses a new prognostic canopy capability that includes fully prognostic and tightly coupled carbon and nitrogen cycles in plants, litter, and soil organic matter (referred to as CLM-CN). All previously published prognostic canopy implementations in coupled climate system models have included only the carbon cycle, ignoring feedback mechanisms with the nitrogen cycle that act primarily to limit the rate of organic matter accumulation in terrestrial ecosystems. Thornton et al. (2002) and Thornton and Rosenbloom (2005) provide detailed descriptions of the mechanisms involved in this coupling, as implemented in the offline biome biogeochemical cycle (BiomeBGC) model.

\section{Methods}

\section{a. Measurement of canopy vertical gradients in $S L A$ and $C N_{\mathrm{L}}$}

Our new canopy integration theory consists of several hypotheses, relating SLA to $x$ [Eq. (1)], and connecting this variation to canopy function through $V_{\text {cmax }}$ [Eqs. (6)-(9)], and to canopy structure through $C_{L}$ and $L$ [Eqs. (2), (3), and 10)]. As a preliminary test of these hypotheses, we measured the vertical distributions of SLA, $\mathrm{CN}_{L}$, and $L$ for five tree species across multiple forested sites in Switzerland. Measurements were made for Fagus sylvatica (European beech), Quercus pubescens (downy oak), Picea abies (Norway spruce), Abies alba (silver fir), and Pinus sylvesrtis (Scots pine), at a total of 11 sites. Here, $L$ was measured at each site using the LiCor LAI-2000 instrument (Table 1).

All sites except Rameren are part of the Long-Term Forest Ecosystem Monitoring Research, framed within the international Cooperative Program on Assessment 
TABLE 1. Site characteristics and species sampled.

\begin{tabular}{|c|c|c|c|c|c|c|c|}
\hline Site name & Lat $\left(\mathrm{N}^{\circ}, "\right)$ & Lon $\left(\mathrm{E}^{\circ}, "\right)$ & $\operatorname{Elev}^{\mathrm{a}}(\mathrm{m})$ & Tmean $^{\mathrm{b}}\left({ }^{\circ} \mathrm{C}\right)$ & $\operatorname{Pann}^{\mathrm{c}}\left(\mathrm{mm} \mathrm{yr}^{-1}\right)$ & $L^{\mathrm{d}}$ & Species sampled ${ }^{\mathrm{e}}$ \\
\hline Alptal & +470260 & +084249 & 1160 & 5.3 & 2129 & 3.5 & PA, AA \\
\hline Bettlachstock & +471335 & +072503 & 1149 & 6.0 & 1454 & 6.5 & $\mathrm{FS}, \mathrm{PA}, \mathrm{AA}$ \\
\hline Isone & +460734 & +090033 & 1220 & 7.5 & 1819 & 5.8 & FS \\
\hline Lausanne & +463506 & +063932 & 807 & 8.6 & 1062 & 6.9 & FS \\
\hline Neunkirch & +474106 & +083213 & 582 & 8.3 & 1020 & 5.2 & FS \\
\hline Novaggio & +460126 & +085008 & 950 & 9.1 & 1887 & 4.9 & QP \\
\hline Othmarsingen & +472403 & +081340 & 484 & 8.6 & 1045 & 4.6 & FS \\
\hline Schänis & +470958 & +090405 & 733 & 7.0 & 1965 & 5.5 & FS \\
\hline Visp & +461753 & +075134 & 715 & 8.8 & 615 & 2.3 & QP, PS \\
\hline Vordemwald & +471632 & +075316 & 480 & 8.4 & 1106 & 5.1 & $\mathrm{FS}, \mathrm{PA}, \mathrm{AA}$ \\
\hline Rameren & +472146 & +082701 & 540 & 8.3 & 1082 & 4.4 & FS \\
\hline
\end{tabular}

a Elevation: average of high and low values for site.

b Mean annual air temperature (1961-90).

${ }^{c}$ Annual total precipitation (1961-90).

${ }^{\mathrm{d}}$ Leaf area index.

${ }^{\mathrm{e}} \mathrm{FS}=$ Fagus sylvatica, $\mathrm{QP}=$ Quercus pubescens, $\mathrm{PA}=$ Picea abies, $\mathrm{AA}=$ Abies alba, and $\mathrm{PS}=$ Pinus sylvestris.

and Monitoring of Air Pollution on Forests. Leaf samples were collected at the top and bottom of the canopy for each species measured at each site, and transported to the laboratory, where measurements were made of one-sided leaf area, dry mass, and mass fractions of carbon and nitrogen. We sampled material from five dominant canopy trees per site, and collected leaf and needle material from three branches per canopy position. We collected a minimum of 50 leaves or circa 200 needles per canopy position. From these measurements SLA was calculated for each leaf sample as the sample one-sided area divided by the sample carbon mass and $\mathrm{CN}_{L}$ was calculated as the mass ratio of carbon to nitrogen. The material from different needle years was pooled for this study, since we did not detect significant and consistent differences in SLA and $\mathrm{CN}_{L}$ between first year and older needles.

Each sample taken at the top of the canopy was assigned a value of $x=0$, and each sample taken at the bottom of the canopy was assigned a value of $x=L$. At two sites (Rameren and Vordemwald) additional leaf samples were collected at canopy locations approximating $x=(1 / 3) L$ and $x=(2 / 3) L$, in an effort to better resolve the within-site functional form for vertical gradients in SLA and $\mathrm{CN}_{L}$. For analysis, data were pooled by species across sites and independent linear regressions were performed for SLA and $\mathrm{CN}_{L}$ versus $x$ for each species.

\section{b. Sensitivity tests with CCSM/CLM}

A series of global-scale simulations was performed within the CCSM3 framework to quantify the effects of introducing the new canopy integration scheme. Offline simulations, forced with National Centers for Environ- mental Prediction-National Center for Atmospheric Research (NCEP-NCAR) reanalysis surface weather fields (Kalnay et al. 1996), were performed for both diagnostic and prognostic canopy models (designated "D" and "P," respectively). Diagnostic canopy simulations were $40 \mathrm{yr}$ in length, with results from the final 20 yr used for analysis. A 20-yr subset of the reanalysis dataset (1980-99) was extracted and repeated twice to provide $40 \mathrm{yr}$ of surface weather forcing. Prognostic canopy simulations were brought to steady state (absolute value of global net carbon flux $<0.01 \mathrm{PgC} \mathrm{yr}^{-1}$ ) using the methods described in Thornton and Rosenbloom (2005), and cycling as necessary through the 20yr surface weather dataset, with results from the final 20 yr used for analysis. The geographic distributions of land surface types, plant functional types, and, for the diagnostic model, remote sensing-derived monthly climatology of $L$ are identical to those used in Dickinson et al. (2006). Spatial resolution for all simulations is approximately $3.75^{\circ} \times 3.75^{\circ}$.

While the measurement campaign performed for this study provides a preliminary test of our main hypotheses, it does not provide parameterizations for the global range of vegetation types required by CLM. We used PFT-level mean values of SLA, $\mathrm{CN}_{L}$, and $F_{\mathrm{LNR}}$ from a literature synthesis of physiological parameters (White et al. 2000). Because measurements of SLA reported in White at al. (2000) are generally taken from the sunlit canopy, we assume that SLA from this source is a good approximation of $\mathrm{SLA}_{0}$. Having at this point no reliable global parameter estimates for the slope $(m)$ of SLA versus $x$, we estimated $m$ for forest and shrub PFTs by assuming a factor-of-2 increase in SLA from the top to the bottom of a dense canopy $(L \sim 8$; White 
TABLE 2. Leaf-level physiological parameters by PFT.

\begin{tabular}{lcccc}
\hline \hline \multicolumn{1}{c}{ PFT } & $\mathrm{SLA}_{0}\left(\mathrm{~m}^{2} \mathrm{gC}^{-1}\right)$ & $m$ & $\mathrm{CN}_{L}\left(\mathrm{gC}_{\mathrm{gN}}{ }^{-1}\right)$ & $F_{\mathrm{LNR}}$ (prop.) \\
\hline Needleleaf evergreen tree (temperate) & 0.010 & 0.0013 & 35 & 0.05 \\
Needleleaf evergreen tree (boreal) & 0.008 & 0.0010 & 40 & 0.04 \\
Needleleaf deciduous tree & 0.024 & 0.0030 & 25 & 0.08 \\
Broadleaf evergreen tree (tropical) & 0.012 & 0.0015 & 30 & 0.06 \\
Broadleaf evergreen tree (temperate) & 0.012 & 0.0015 & 30 & 0.06 \\
Broadleaf deciduous tree (tropical) & 0.030 & 0.0040 & 25 & 0.09 \\
Broadleaf deciduous tree (temperate) & 0.030 & 0.0040 & 25 & 0.09 \\
Broadleaf deciduous tree (boreal) & 0.030 & 0.0040 & 25 & 0.09 \\
Broadleaf evergreen shrub & 0.012 & 0.0015 & 30 & 0.06 \\
Broadleaf deciduous shrub (temperate) & 0.030 & 0.0040 & 25 & 0.09 \\
Broadleaf deciduous shrub (boreal) & 0.030 & 0.0040 & 25 & 0.09 \\
C3 arctic grass & 0.050 & 0.0000 & 25 & 0.09 \\
C3 nonarctic grass & 0.050 & 0.0000 & 25 & 0.09 \\
C4 grass & 0.050 & 0.0000 & 25 & 0.09 \\
Crop & 0.050 & 0.0000 & 25 & 0.10 \\
\hline
\end{tabular}

et al. 2000). New model parameters are summarized by PFT in Table 2.

We performed a control simulation for each model configuration (simulations D0 and P0) using the canopy integration logic of the CLM3 release model. We then substituted our new model for the original CLM3 logic and repeated the simulations. These simulations (D1 and P1) fix the CLM3 inconsistency in leaf-scale APAR and include both the two-leaf (sun/shade) model and vertical gradient in SLA.

\section{Results}

\section{a. Observed canopy gradients of SLA and $C N_{\mathrm{L}}$}

Measurements on five tree species over a total of 11 sites show that there is a significant $(P<0.01)$ linear relationship between SLA and $x$ for all species, with variation between species in $\mathrm{SLA}_{0}$ and $m$ (Table 3). These measurements also show that there is not a significant linear relationship between $\mathrm{CN}_{L}$ and $x$ for any species. We also found no significant linear relationships between $\mathrm{CN}_{L}$ and SLA within species (results not shown).

Figure 2 shows the observed within-species variability in SLA versus $x$ for four species and demonstrates that there are no obvious biases in the residuals from the linear model. The slope $m$ of the SLA versus $x$ relationship is larger for the two deciduous broadleaf species than for the three evergreen needleleaf species, and the evergreens are more similar in their slope than are the deciduous species. In spite of the differences in slope, the strength of the linear relationship is very similar between species, with adjusted $\mathrm{R}^{2}$ ranging from 0.78 to 0.88 .

\section{b. Effects of coding error for leaf-scale APAR in CLM3}

The influence of inconsistent treatment of the area basis for APAR in CLM3 was isolated by comparing output from the released model with a modified model

TABLE 3. Regression results from canopy gradient measurements for five species, where the sample size $(n)$ for each regression is based on measurements at multiple canopy positions across multiple sites. Regression intercept and slope are shown with standard error (SE), together with adjusted $R^{2}$. Significant relationships $(P<0.01$ for slope) are shown in bold. For the SLA vs $x$ regressions, intercept corresponds to $\mathrm{SLA}_{0}\left(\mathrm{~m}^{2}\right.$ one-sided leaf area $\left.\mathrm{gC}^{-1}\right)$ and slope corresponds to $\mathrm{m}$.

\begin{tabular}{|c|c|c|c|c|c|c|}
\hline Regression & Species & $n$ & Intercept (SE) & Slope (SE) & $\operatorname{Adj} R^{2}$ & $P$ value \\
\hline \multirow[t]{5}{*}{ SLA vs $x$} & Fagus sylv. & 32 & $0.0248(0.0017)$ & $0.0071(0.0005)$ & 0.87 & $<0.0001$ \\
\hline & Quer. pub. & 14 & $0.0199(0.0009)$ & $0.0027(0.0003)$ & 0.88 & $<0.0001$ \\
\hline & Picea ab. & 26 & $0.0078(0.0005)$ & $0.0016(0.0002)$ & 0.78 & $<0.0001$ \\
\hline & Abies alb. & 14 & $0.0091(0.0005)$ & $0.0011(0.0001)$ & 0.81 & $<0.0001$ \\
\hline & Pinus sylv. & 6 & $0.0061(0.0003)$ & $0.0010(0.0002)$ & 0.85 & 0.0058 \\
\hline \multirow{5}{*}{$\mathrm{CN}_{L}$ vs $x$} & Fagus sylv. & 15 & $20.2(0.4)$ & $-0.1(0.1)$ & 0.05 & 0.213 \\
\hline & Quer. pub. & 13 & $20.0(0.5)$ & $0.1(0.2)$ & 0.00 & 0.614 \\
\hline & Picea ab. & 14 & $44.5(2.0)$ & $-0.3(0.7)$ & 0.00 & 0.660 \\
\hline & Abies alb. & 6 & $36.5(3.2)$ & $0.1(0.9)$ & 0.00 & 0.900 \\
\hline & Pinus sylv. & 6 & $35.2(1.7)$ & $0.4(1.0)$ & 0.00 & 0.705 \\
\hline
\end{tabular}



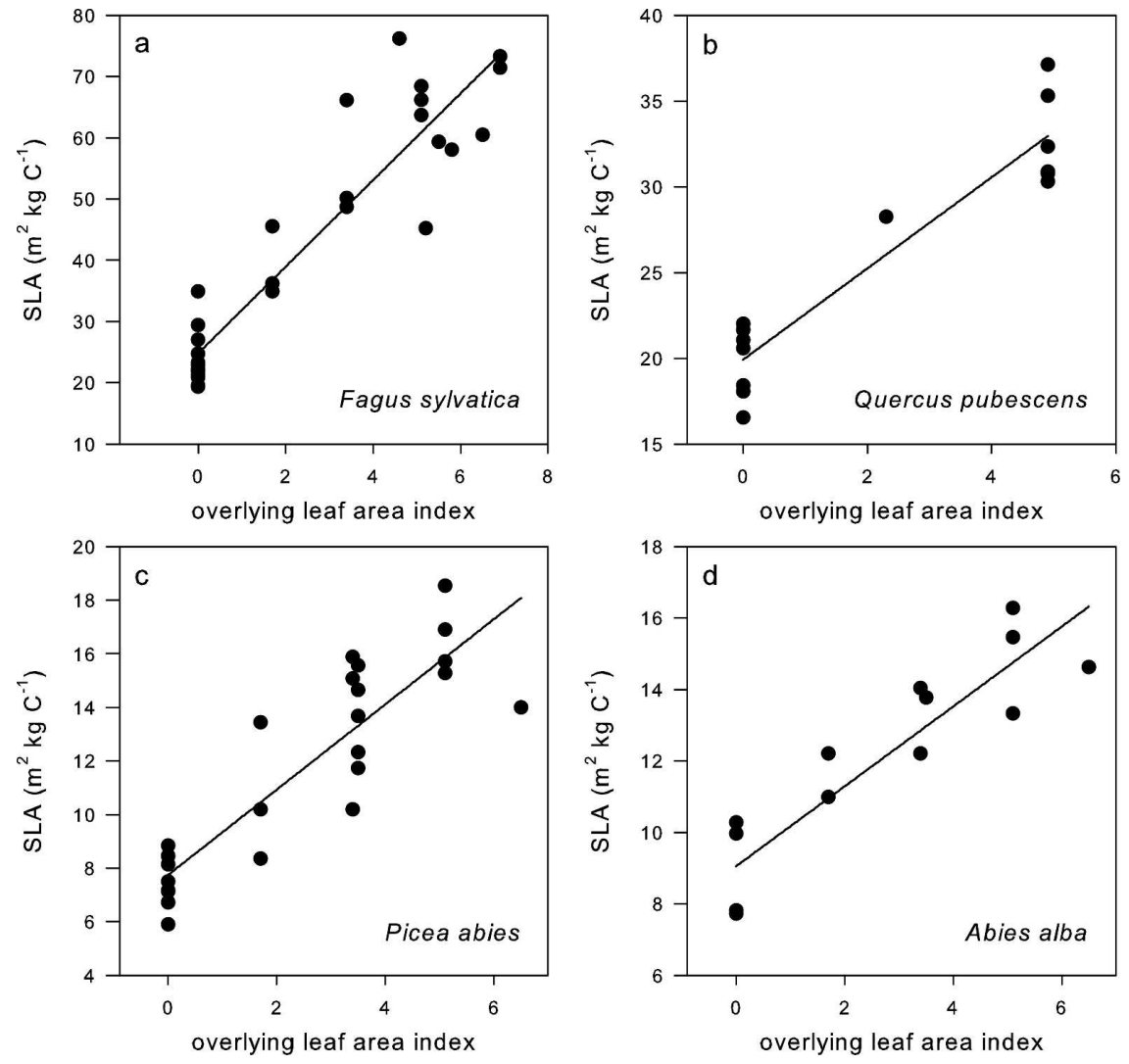

FIG. 2. Measured SLA (one-sided area and carbon mass basis) plotted against overlying leaf area for (a), (b) two deciduous species and (c), (d) two evergreen species, with species-specific regression lines. Each plot shows measurements taken at multiple sites and multiple canopy levels.

that corrects the area basis for APAR but leaves in place the intended (but unusual) single big-leaf behavior of CLM3. This coding error produces biases in GPP that vary with $L$, PAR, and solar zenith angle (Fig. 3). The most serious problem caused by this error is the underestimation of GPP at low $L$, with bias approaching $-100 \%$ as $L$ approaches zero (Fig. 3a). This effect is most significant for low-productivity ecosystems with perennially low $L$, for deciduous vegetation in the early and late growing seasons, and for ecosystems recovering from recent disturbance. In addition, for the case of a prognostic canopy model, the underestimation bias results in unsustainably low GPP for canopies initiated from low $L$. This bias prevents the successful spinup of the control experiment for the prognostic canopy model (experiment $\mathrm{P} 0$ ).

For moderate PAR, the error produces a strong negative bias in GPP early in the day, when $L_{\text {sun }}<1.0$, but around midday the uncorrected and corrected GPP are identical (Fig. 3b). Insensitivity to $f_{\text {dir }}$ (Fig. 3a) and negligible bias around midday are due to the unusual implementation of the single big-leaf model, in which all of the canopy-intercepted radiation is assigned to the sunlit canopy fraction, leading to saturating levels of PAR per unit leaf area in that fraction. Only under very low levels of PAR does the coding error produce a positive daily GPP bias (results not shown).

\section{c. Effects of a two-leaf versus one-leaf canopy model}

With the code error for leaf-scale APAR corrected, we assessed the bias associated with the unusual single big-leaf implementation in CLM3, compared to a typical two-big-leaf model as proposed by Dai et al. (2004). We first show results for the case of a canopy with constant photosynthetic capacity with depth, as in CLM3, and in the next section we address the influence of introducing a vertical gradient in $V_{\text {cmax }}$ tied to $\operatorname{SLA}(x)$.

The difference in daily total GPP between the CLM3 single big-leaf model (1L) and the Dai et al. sun-shade model ( $2 \mathrm{~L}$ ) is very small at low PAR when both models 

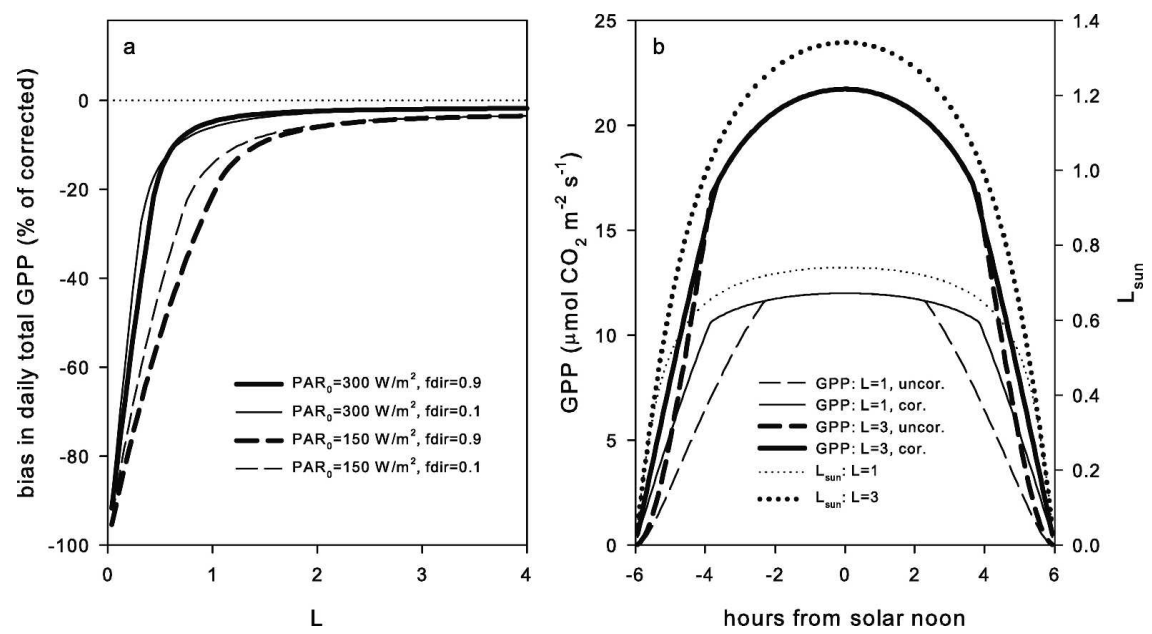

FIG. 3. (a) Bias in GPP introduced by inconsistent treatment of APAR in CLM3, shown over a range in $L$, as a percent of corrected daily total GPP for a typical broadleaf C3 physiological parameterization. Reference line shown at zero bias. $\mathrm{PAR}_{0}=\mathrm{PAR}$ at noon. (b) Uncorrected (uncor.) and corrected (cor.) diurnal variation in GPP for the case of $\mathrm{PAR}_{0}=$ $150 \mathrm{~W} \mathrm{~m}^{-2}$ and fraction direct $\left(f_{\text {dir }}\right)=0.1$.

are in the range of linear response to PAR (Fig. 4a), and at low $L$ where $L_{\text {sun }}$ approaches $L$ (Fig. $4 \mathrm{~b}$ ). At higher PAR GPP from $1 \mathrm{~L}$ quickly saturates since all intercepted radiation is being assigned to $L_{\text {sun }}$, while GPP from 2L continues to increase (Fig. 4a) as APAR for the shaded canopy is far from saturation levels. Sensitivity to $f_{\text {dir }}$ is very low for $1 \mathrm{~L}$ because the sum of intercepted direct and diffuse are assigned to $L_{\text {sun }}$ (differences between $f_{\mathrm{dir}}=0.9$ and 0.1 are imperceptible for $1 \mathrm{~L}$ in Fig. $4 \mathrm{a}$ ), while $2 \mathrm{~L}$ shows strong sensitivity to $f_{\text {dir }}$, with higher GPP at larger fraction diffuse (Fig. 4a). The response to $f_{\text {dir }}$ in $2 \mathrm{~L}$ is due to more uniform distribution of APAR between sunlit and shaded canopy fractions under larger fraction diffuse, reducing the
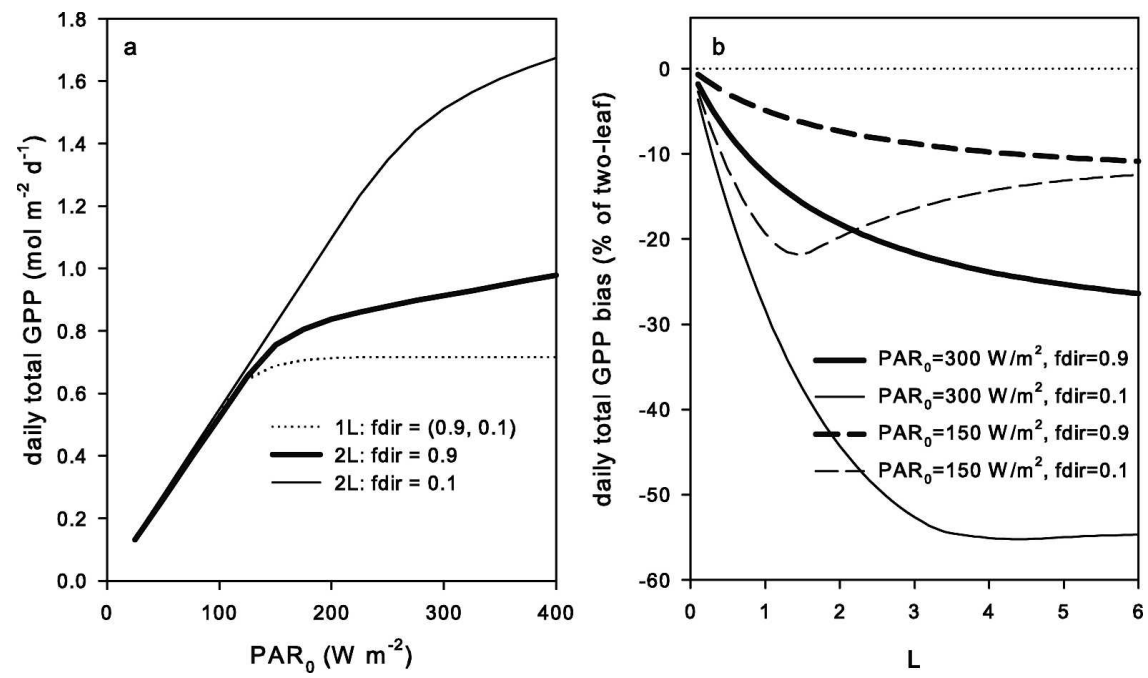

FIG. 4. Comparison of CLM3 one-leaf model (1L) against standard two-leaf model (2L), with $V_{\text {cmax }}$ constant with canopy depth in both $1 \mathrm{~L}$ and $2 \mathrm{~L}$. (a) Daily total GPP from $1 \mathrm{~L}$ and $2 \mathrm{~L}$ models over a range of $\mathrm{PAR}_{0}$ and two values of $f_{\text {dir }}$, for $L=3.0$. (b) Variation with $L$ in bias due to $1 \mathrm{~L}$ vs $2 \mathrm{~L}$ model, for selected values of $\mathrm{PAR}_{0}$ and $f_{\text {dir }}$. Reference line shown at zero bias. 



FIG. 5. Bias in daily total GPP due to assumed constant $V_{\text {cmax }}$ with canopy depth, compared to vertical gradient in $V_{\text {cmax }}$ tied to $\operatorname{SLA}(x)$. SLA $(x)$ uses the linear fit to observations for Fagus sylvatica (Table 3 ). Results are shown using two values for assumed constant $V_{\text {cmax }}$, based on assumed constant SLA: (a) the top-of-canopy value from linear fit $\left(\mathrm{SLA}_{0}\right)$, and (b) the mean value from canopy gradient measurements of SLA. Legend in (b) applies to both plots. Reference line shown at zero bias.

overall degree of light saturation in the canopy, as demonstrated also by de Pury and Farquhar (1997) and Dai et al. (2004).

Bias for daily total GPP from $1 \mathrm{~L}$ versus $2 \mathrm{~L}$ is always negative, ranging up to $-55 \%$ at high PAR and low $f_{\text {dir }}$ (Fig. 4b). This is in contrast to results from previous one-leaf versus two-leaf comparisons (e.g., Reynolds et al. 1992; de Pury and Farquhar 1997), which find that the one-leaf model typically overestimates GPP. The difference here is due to the unusual formulation of $1 \mathrm{~L}$ in CLM3 - in all other one-leaf models that we are aware of, intercepted radiation is distributed over the entire canopy leaf area, not assigned to $L_{\text {sun }}$.

\section{d. Effects of canopy vertical gradient in SLA}

Given a sun-shade canopy treatment as in Dai et al. (2004), and using Eq. (1) to describe SLA $(x)$ and Eq. (8) to integrate SLA over the sunlit and shaded canopy fractions, we describe the vertical gradient in photosynthetic potential as the dependence of $V_{\text {cmax }}$ on SLA sun and SLA $_{\text {sha }}$ through Eq. (7). For the constant $V_{\text {cmax }}$ model (as in CLM3) we use an assumed canopy constant value of SLA and Eq. (7). There is no single value of constant SLA that produces acceptably low biases compared to the vertical gradient model over typical ranges of $L, \mathrm{PAR}_{0}$, and $f_{\text {dir }}$ (Fig. 5). Using the top-ofcanopy SLA produces positive biases that exceed $20 \%$ at moderate to high $L, \mathrm{PAR}_{0}$, and $f_{\text {dir }}$ (Fig. 5a). The bias under these conditions is mainly due to a lower $V_{\text {cmax }}$ for the sunlit canopy fraction in the vertical gradient model. Using canopy-mean SLA produces negative biases that exceed $20 \%$ at low $L$ and high PAR $_{0}$ (Fig. 5b), caused mainly by a higher $V_{\text {cmax }}$ in the sunlit canopy fraction for the vertical gradient model.

The vertical gradient approach described above for $V_{\text {cmax }}$ is subject to bias due to the nonlinearity of $V_{\text {cmax }}$ (SLA) through Eq. (7). This bias is eliminated by integrating Eq. (8) directly, but as noted there is no analytical solution. We compared calculation of instantaneous values for $N_{a \text {,sun }}$ and $N_{a \text {,shade }}$ using the approximation of Eq. (9) and the more exact numerical integration of Eq. (8), and found that the bias from this approximation is negative and increases in magnitude with high $L$ and low solar zenith angle. Based on tests using the vertical canopy gradients in our observations, instantaneous error in $N_{a}$ is $<8 \%$, with the worst case being midday estimates for a high- $L$ canopy using the Fagus sylvatica parameterization (Fig. 6). The resulting biases in daily total GPP are $<5 \%$.

In addition to the effects of vertical variation in SLA on canopy photosynthesis through $V_{\text {cmax }}$, there is also an important effect on the calculation of $L$ as a function of SLA and total canopy leaf carbon $\left(C_{L}\right)$ in the prognostic model [Eq. (3)]. Total canopy leaf area can be underestimated by greater than $50 \%$ for dense canopies 




FIG. 6. Bias in calculation of instantaneous $N_{a}$, caused by integration over SLA $(x)$ as opposed to direct integration over $N_{a}(x)$. Results shown are for the Fagus sylvatica parameterization (Table 3) at midday.

when assuming, for example, a constant value for SLA obtained from the sunlit canopy. The combined effects of bias in $L$ and $V_{\text {cmax }}$ on GPP due to assumption of constant SLA in the prognostic canopy model vary with prognostic canopy leaf carbon and depend strongly on the constant SLA selected, $\mathrm{PAR}_{0}$, and $f_{\text {dir }}$ (Fig. 7). Magnitude of GPP bias is increased in some cases compared to the diagnostic model (Fig. 5), for example, at low $\mathrm{PAR}_{0}$ with SLA $=\mathrm{SLA}_{\text {sun }}$ (Fig. 7a), and is reduced in other cases, for example, at high $\mathrm{PAR}_{0}$ with SLA set to the canopy mean value (Fig. 7b). These differences are the result of different $L$ for the same $C_{L}$ in the prognostic model with and without vertical gradient in SLA.

\section{e. Cumulative effects}

The combination of error in the leaf-scale APAR, the unusual big-leaf model, and neglecting vertical canopy gradient in leaf morphology and photosynthetic capacity produces large biases in GPP for CLM3, compared to the two-leaf model with explicit representation of SLA $(x)$ introduced here (Fig. 8). The CLM3 leafscale APAR error overwhelms other factors at $L<1.0$, with bias approaching $-100 \%$ for both diagnostic and prognostic models at all values of $\mathrm{PAR}_{0}$ and $f_{\text {dir }}$. Biases are quite variable at low-to-moderate $L$ (or $C_{L}$ ), and are generally more negative at higher $\mathrm{PAR}_{0}$ and larger fraction diffuse. Biases tend to stabilize at moderateto-high $L$ ( or $C_{L}$ ), with bias magnitude at high $L$ depending strongly on the choice of constant $V_{\text {cmax }}$ or SLA. Biases at high $L$ for typical parameterization choices range from $\sim 20 \%$ for low $\mathrm{PAR}_{0}$ and using the sunlit SLA as a constant for the entire canopy (Fig. 8a), to $\sim-40 \%$ to $-50 \%$ for high $\mathrm{PAR}_{0}$ and using the canopy mean SLA as a constant for the entire canopy.


FIG. 7. Bias in daily total GPP for the prognostic canopy model due to assumed constant SLA with canopy depth, compared to vertical gradient SLA $(x)$. SLA $(x)$ uses the linear fit to observations for Fagus sylvatica (Table 3). Results are shown using two values for assumed constant SLA: (a) the top-of-canopy value from linear fit $\left(\mathrm{SLA}_{0}\right)$, and (b) the mean value from canopy gradient measurements of SLA. Legend in (b) applies to both plots. Reference line shown at zero bias. 

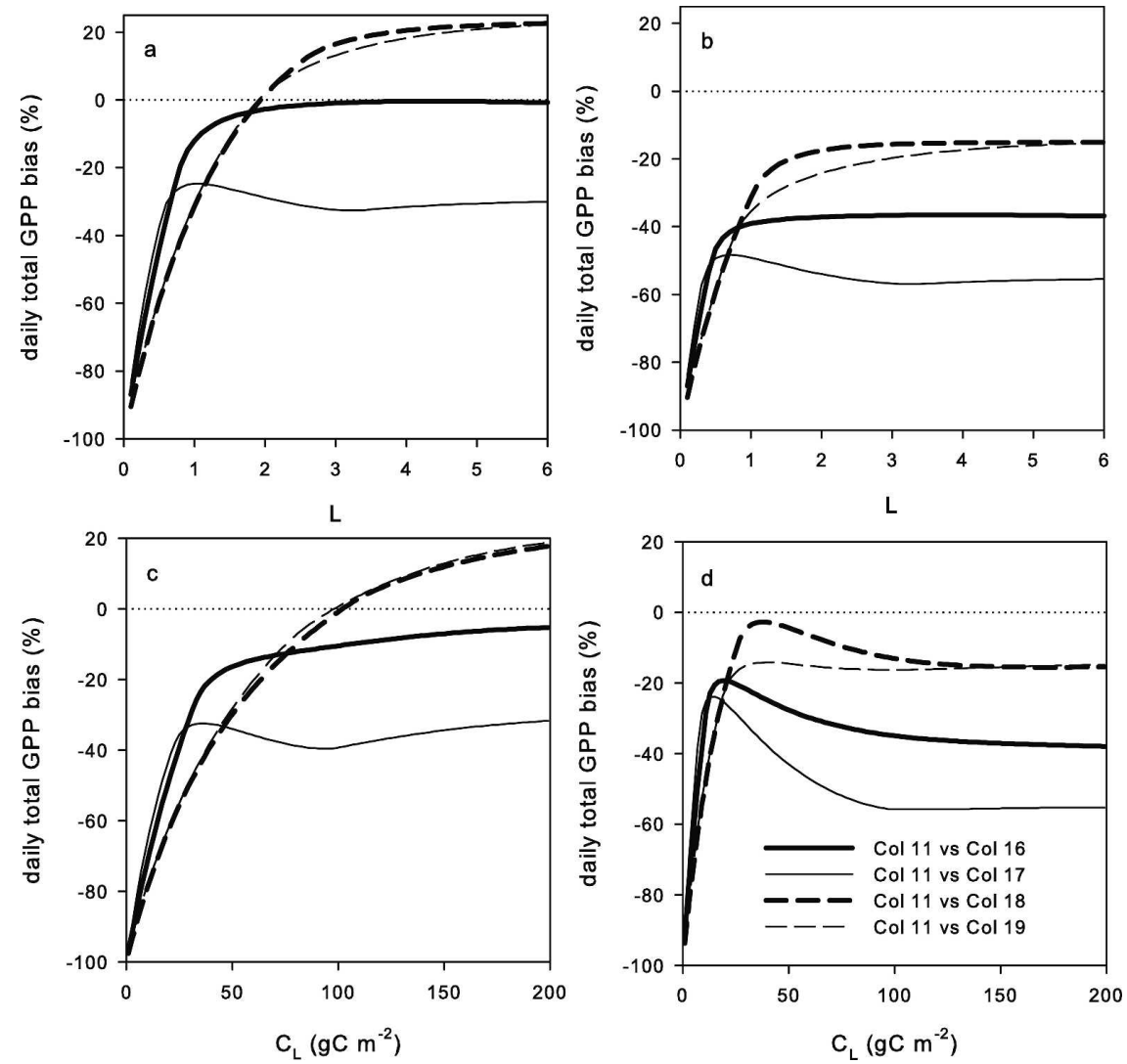

FIG. 8. Cumulative bias in daily total GPP due to CLM3 error for leaf-scale APAR, $1 \mathrm{~L}$ vs $2 \mathrm{~L}$ model, and constant SLA vs $\operatorname{SLA}(x)$. SLA $(x)$ is as in Fig. 5. (a), (b) Diagnostic canopy model. (c), (d) Prognostic canopy model. Results for both diagnostic and prognostic models are shown using two values for assumed constant SLA: (a), (c) the top-of-canopy value from linear fit $\left(\mathrm{SLA}_{0}\right)$, and $(\mathrm{b}),(\mathrm{d})$ the mean value from canopy gradient measurements of SLA. Legend in (d) applies to all plots. Reference line shown at zero bias.

These results are qualitatively and quantitatively similar for the diagnostic and prognostic canopy models.

\section{f. Evaluation of global simulations}

Introduction of our new canopy integration scheme increased global total GPP by $66 \%$ compared to the CLM3 release model for simulations using the diagnostic canopy mode (D0 versus D1; Fig. 9). Because of the severe bias in GPP at low $L$ from the CLM3 APAR error, the control experiment for the prognostic canopy model failed to attain significant levels of GPP during the spinup process, and results for this experiment (P0) are not shown. With the new canopy integration model in place the prognostic canopy model follows the expected spinup trajectory (Thornton and Rosenbloom 2005), and the resulting geographic distribution of GPP is similar to that obtained for the diagnostic model (P1 versus D1; Fig. 9). Global total GPP in P1 is $8 \%$ higher than in D1, with GPP generally higher in the Tropics and lower for arctic tundra than in D1.

Global total GPP in D0 ( $\left.66 \mathrm{PgC} \mathrm{yr}^{-1}\right)$ is substantially lower than the recent observation-based estimate of $120 \mathrm{PgC} \mathrm{yr}^{-1}$ cited by Houghton et al. (2001), while experiments D1 and P1 result in total GPP much closer to this estimate (108 and $117 \mathrm{PgC} \mathrm{yr}^{-1}$, respectively). We are not able to further dissect the carbon budget for the simulations performed in diagnostic canopy mode (D0 and D1) since that model does not include a complete treatment of the carbon cycle. The prognostic model does include detailed treatment of multiple carbon state and flux variables, and here we evaluate model predictions of net primary production (NPP) and steady-state accumulations of carbon in live biomass $\left(C_{\text {veg }}\right)$ from experiment P1.

The geographic distribution of NPP in P1 broadly follows the distribution of GPP (Fig. 10), with NPP representing a smaller fraction of GPP in the Tropics 


\section{Diagnostic Canopy, Control (D0): $65 \mathrm{PgC} / \mathrm{yr}$}

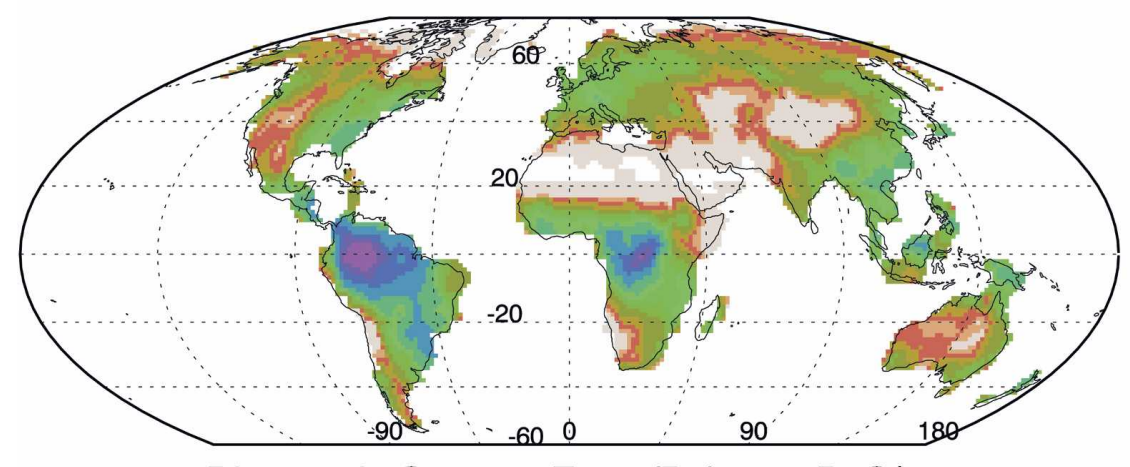

Diagnostic Canopy, Expt. (D1): 108 PgC/yr

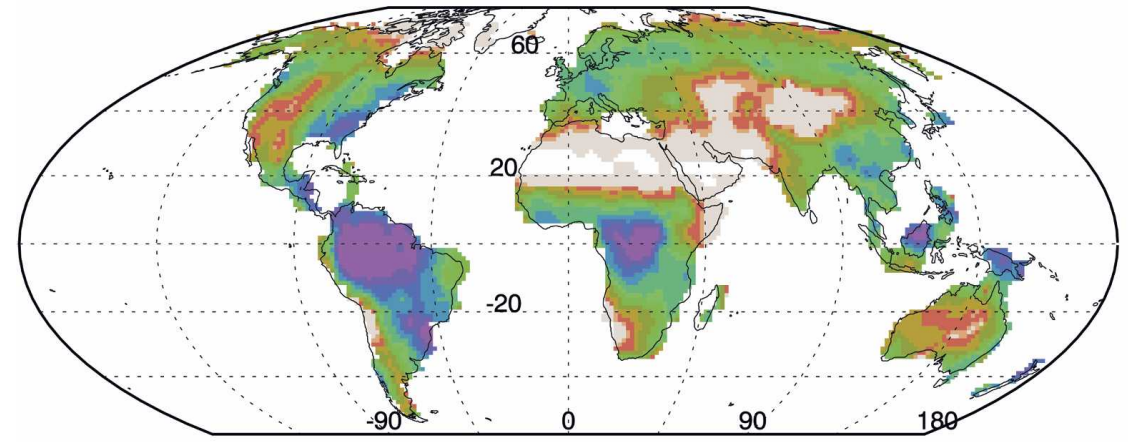

Prognostic Canopy, Expt. (P1): 117 PgC/yr
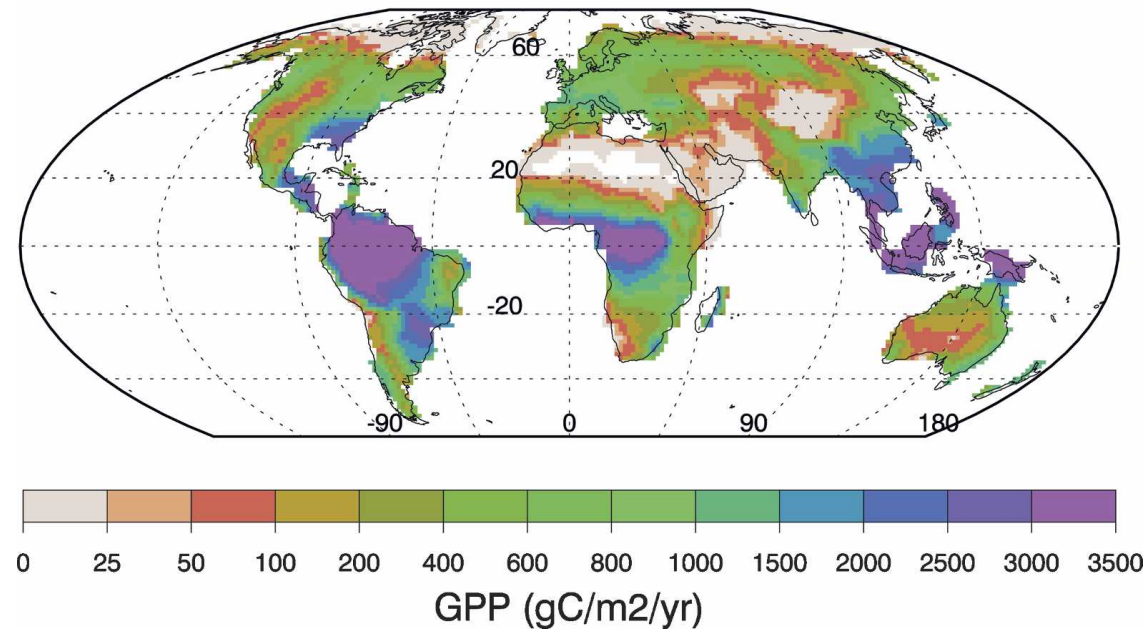

FIG. 9. Simulated GPP from global simulations using (top) the CLM3 release model, and with the new canopy integration model in both (middle) diagnostic and (bottom) prognostic canopy modes. Global total GPP shown in title for each panel.

than elsewhere due to the modeled temperature dependence of autotrophic respiration. $C_{\mathrm{veg}}$ distribution broadly follows the geographic patterns of NPP, with the expected correspondence between high $C_{\text {veg }}$ and woody vegetation, and relatively high $C_{\text {veg }}$ in cool temperate forest with low rates of fire occurrence (Fig. 10).

Disaggregating the gridcell-level NPP and $C_{\text {veg }}$ and summarizing by individual plant functional types shows a likely underestimation of productivity for vegetation types that dominate in tundra and the coldest boreal forests (Table 4). NPP is biased obviously low for larch (deciduous needleleaf forest), distributed mainly in far eastern Siberia, and also for arctic grasses and (to a lesser extent) boreal deciduous shrubs, the main com- 
Net Primary Production: 41.2 PgC/yr

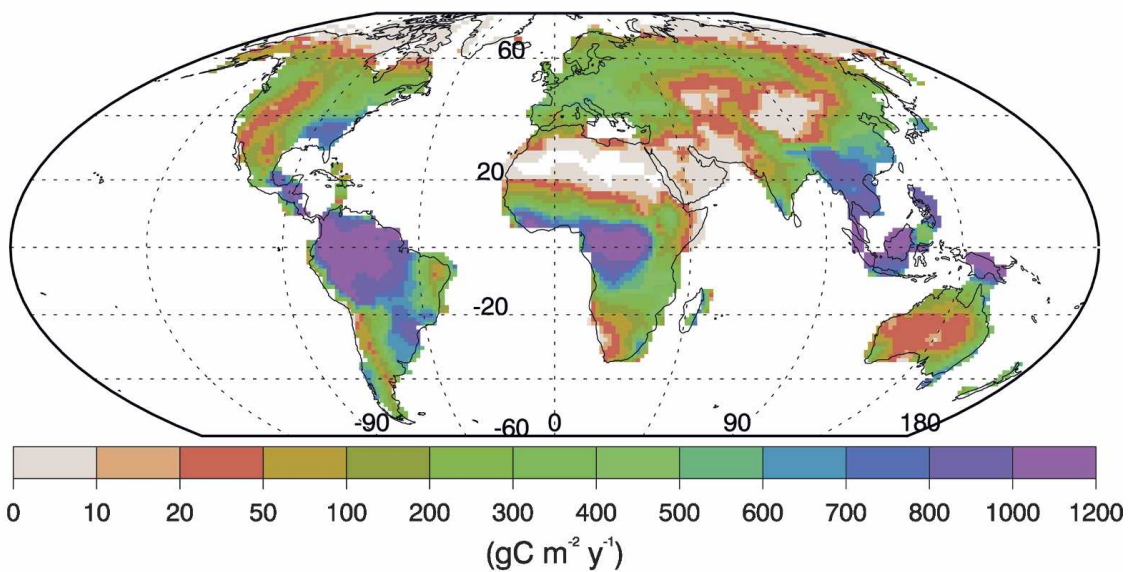

Vegetation Carbon: $731 \mathrm{PgC}$

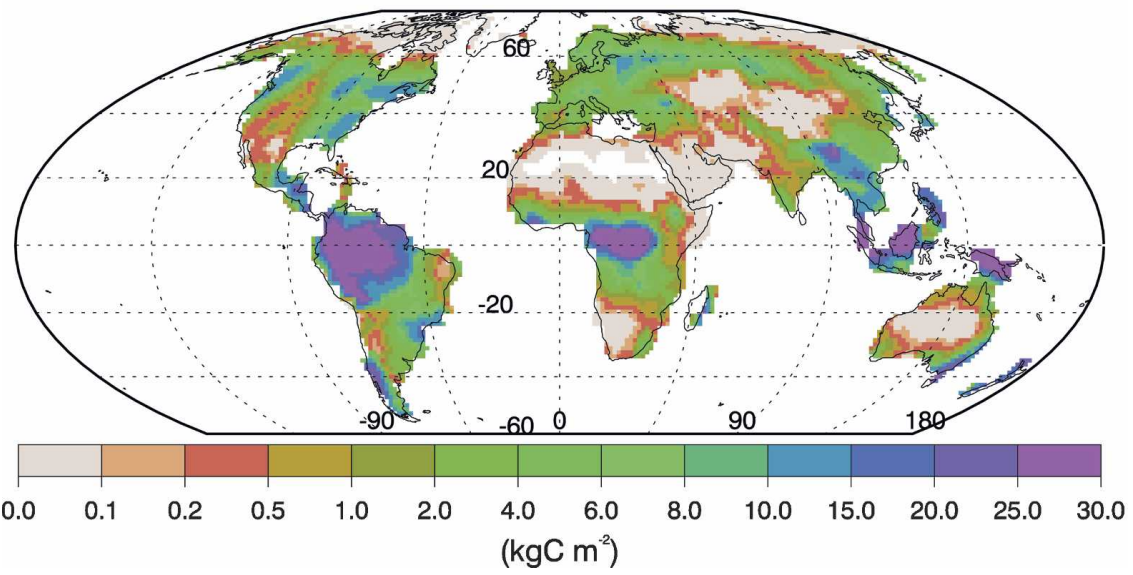

FIG. 10. Simulated (top) NPP and (bottom) $C_{\text {veg }}$ from global simulation using the new canopy integration model in prognostic canopy mode. Global totals for NPP and $C_{\mathrm{veg}}$ shown in panel titles.

ponents of tundra vegetation communities. As a firstorder objective evaluation of the model predictions against observations, we condensed the CLM vegetation types to match the classification used in a recent global synthesis of NPP and $C_{\text {veg }}$ observations (Table 5), produced as part of the Intergovernmental Panel on Climate Change Third Assessment Report (IPCC TAR; Houghton et al. 2001).

It is clear from Table 5 that variation in the total area ascribed to a vegetation class has a strong influence on the global total NPP and $C_{\text {veg }}$ for the class, and that there is considerable variability in areas and totals between the two sets of observation-based estimates. There is generally better agreement between the two sets of observations in NPP and $C_{\text {veg }}$ per unit area. On that basis, model predictions of NPP are seen to fall within or very close to the range from observations for tropical forest, temperate forest, tropical savannas/ grasslands, and croplands, with NPP overestimated for boreal forest and underestimated for temperate grasslands/shrublands and tundra (Fig. 11a). Although the model captures the relative distribution of $C_{\mathrm{veg}}$ between vegetation classes quite well, predicted $C_{\mathrm{veg}}$ is generally higher than observed, particularly for forest types (Fig. 11b). We expected that underpredictions in NPP for temperate grasslands/shrublands and tundra would correspond to underpredictions in $C_{\mathrm{veg}}$, but the grass/shrub carbon density is within range of observations (for both tropical and temperate grass communities), while tundra carbon density is higher than observed.

\section{Discussion}

Our measurements suggest that, at least for temperate forest species, the hypothesis of linear variation of 
TABLE 4. Predicted NPP and $C_{\text {veg }}$ from simulation P1, summarized by CLM vegetation type. Also shows mapping of CLM types to IPCC types, referencing IPCC type numbers in Table 5.

\begin{tabular}{|c|c|c|c|c|c|c|}
\hline CLM vegetation type & $\begin{array}{l}\text { IPCC } \\
\text { type }\end{array}$ & $\begin{array}{c}\mathrm{NPP} \\
\left(\mathrm{gC} \mathrm{m}^{-2} \mathrm{yr}^{-1}\right)\end{array}$ & $\begin{array}{c}C_{\mathrm{veg}} \\
\left(\mathrm{kgC} \mathrm{m}^{-2}\right)\end{array}$ & 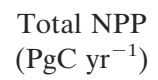 & $\begin{array}{l}\text { Total } C_{\mathrm{veg}} \\
\quad(\mathrm{PgC})\end{array}$ & $\begin{array}{l}\text { Total area } \\
\left(10^{6} \mathrm{~km}^{2}\right)\end{array}$ \\
\hline Bare ground & 8 & 0 & 0.0 & 0.0 & 0.0 & 53.2 \\
\hline Needleleaf evergreen tree (temperate) & 2 & 597 & 18.1 & 1.5 & 44.4 & 2.4 \\
\hline Needleleaf evergreen tree (boreal) & 3 & 407 & 11.8 & 2.5 & 73.1 & 6.2 \\
\hline Needleleaf deciduous tree (larch) & 3 & 40 & 0.8 & 0.0 & 0.8 & 1.0 \\
\hline Broadleaf evergreen tree (tropical) & 1 & 1073 & 36.7 & 9.7 & 332.3 & 9.1 \\
\hline Broadleaf evergreen tree (temperate) & 2 & 1115 & 39.5 & 1.5 & 51.4 & 1.3 \\
\hline Broadleaf deciduous tree (tropical) & $1,4^{*}$ & 622 & 17.8 & 3.7 & 104.9 & 5.9 \\
\hline Broadleaf deciduous tree (temperate) & 2 & 566 & 16.7 & 1.6 & 48.5 & 2.9 \\
\hline Broadleaf deciduous tree (boreal) & 3 & 470 & 14.4 & 0.5 & 16.3 & 1.1 \\
\hline Broadleaf evergreen shrub & 5 & 706 & 17.9 & 0.1 & 2.6 & 0.1 \\
\hline Broadleaf deciduous shrub (temperate) & 5 & 142 & 3.0 & 0.9 & 20.2 & 6.6 \\
\hline Broadleaf deciduous shrub (boreal) & 6 & 65 & 1.8 & 0.5 & 15.1 & 8.3 \\
\hline $\mathrm{C} 3$ arctic grass & 6 & 5 & 0.0 & 0.0 & 0.3 & 7.4 \\
\hline C3 nonarctic grass & 5 & 151 & 0.2 & 2.8 & 3.5 & 18.6 \\
\hline $\mathrm{C} 4$ grass & 4 & 671 & 0.7 & 11.6 & 12.9 & 17.3 \\
\hline Crop & 7 & 467 & 0.5 & 4.1 & 4.5 & 8.9 \\
\hline Global total & & & & 41.2 & 730.8 & 150.2 \\
\hline
\end{tabular}

* The CLM tropical deciduous forest area was divided between IPCC types 1 (tropical forest, 67\%) and 4 (tropical savannas/grasslands, $34 \%)$.

SLA and constant $\mathrm{CN}_{L}$ with $x$ is valid, and furthermore that there is little variation in $\operatorname{SLA}(x)$ across sites for a given species. The hypothesis is supported by measurements from five temperate forest sites situated along a significant precipitation gradient in New Zealand as reported by White and Scott (2006), who found that SLA at the top of the canopy varied little for a given species, while shaded canopy SLA was more variable, with a linear form for SLA $(x)$. Meir et al. (2002) also found an approximately linear variation of $\operatorname{SLA}(x)$ in temperate forest canopies, and they suggest that canopy-bottom foliage can be used to predict canopy carboxylation capacity. Our results and those of White and Scott (2006) suggest that this is true once species-specific values for $\mathrm{SLA}_{0}$ and slopes for $\operatorname{SLA}(x)$ have been determined. Additional measurements or syntheses of existing measurements are needed to better constrain this hypothesis, especially in other climatic regions and for nonforest vegetation. Preliminary evidence presented here supports the implementation of this hypothesis in a global model for the purpose of exploring its ramifications for the global cycling of carbon, water, and energy.

Previous studies have demonstrated that the bias associated with a big-leaf model such as proposed by Sellers et al. (1992) can be largely eliminated by using a two-leaf model that represents the sunlit and shaded canopy fractions separately (de Pury and Farquhar 1997; Wang and Leuning 1998; Dai et al. 2004), and we start from the assumption that the standard two-leaf model with introduction of some vertical gradient in photosynthetic potential is an improvement over the typical one-leaf model. Here we have expanded on the two-leaf model by introducing a treatment of vertical gradient in specific leaf area that explicitly connects the structural and functional characteristics of the canopy. A second significant step forward is the introduction of fully prognostic carbon and nitrogen dynamics into the land process component of an operational climate system model. This coupled carbon-nitrogen logic has been developed over decades in a number of offline ecosystem process models, while recent progress has been made in incorporating carbon cycle dynamics into climate system models. The SLA gradient hypothesis provides a consistent logical framework for merging these developments, bridging the gap between prognostic canopy carbon and nitrogen state variables and canopy photosynthetic potential and biophysical dynamics.

We found it necessary to describe in some detail the existing canopy integration treatment in the released version of CLM3 as that version has been and continues to be used in published studies. Both the APAR error and the unorthodox big-leaf implementation give this model behavior that is unusual when compared to the results of previous canopy integration studies. We consider the introduction of the two-leaf model of Dai et al. (2004) and the introduction of some form of vertical 


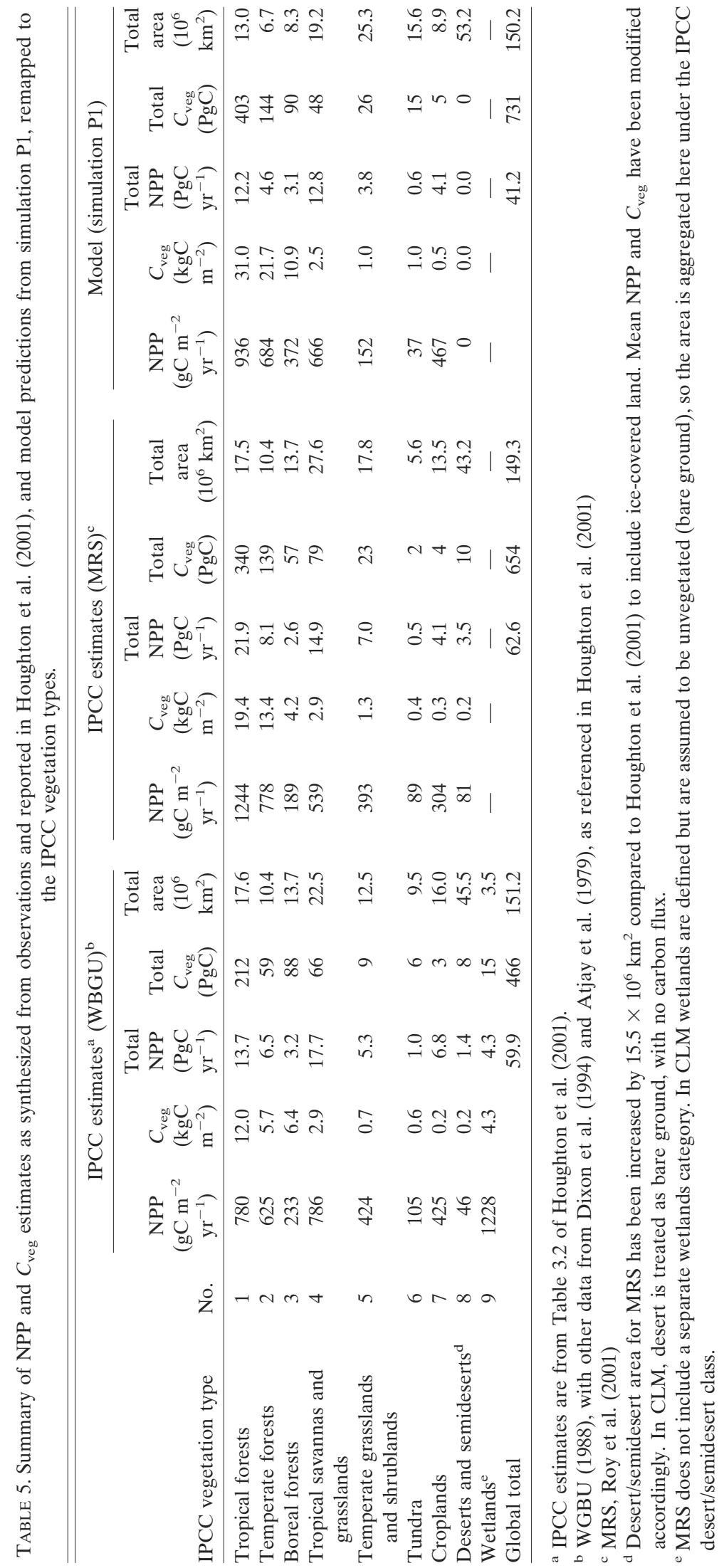



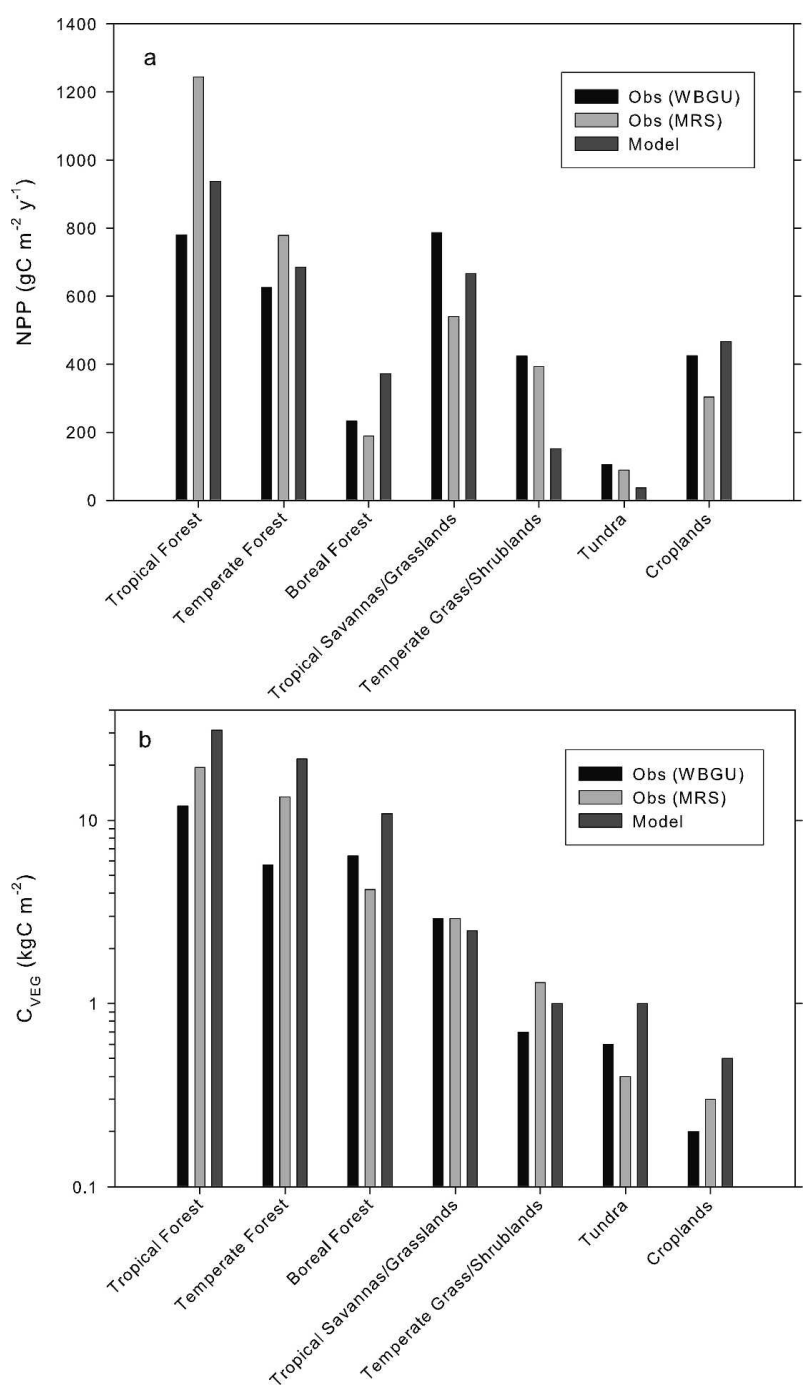

FIG. 11. Comparison of vegetation class means for (a) NPP and (b) $C_{\text {veg }}$ between model predictions from simulation $\mathrm{P} 1$ and two independent sets of observations summarized by Houghton et al. (2001). Model means for each class are based on reclassification of CLM vegetation types to match the IPCC classification (Tables 4 and 5).

gradient in photosynthetic potential to be remedial steps, bringing the model in line with the current stateof-the-art.

While the linear form for $\operatorname{SLA}(x)$ is supported by observations, it leads to an expensive numerical integration to estimate sunlit and shaded canopy nitrogen. An inexpensive analytical approximation is possible by ignoring the nonlinearity of $V_{\text {cmax }}$ (SLA), and while the resulting bias in GPP is small there may be other formulations that match the data nearly as well and provide exact analytical solutions. We explored several alternatives and found that formulations that provided exact integrals for $N_{a}$ required numerical integrations for $L$.

Sensitivity tests with different assumed canopy constant values of SLA demonstrate that there is not a simple correction that could be applied to GPP as predicted by a constant-SLA canopy model to eliminate the expected biases over realistic ranges in $L$ and PAR. Unlike a big-leaf model, our proposed treatment of $\operatorname{SLA}(x)$ maintains the definitions and relationships between key canopy variables across the scaling divide from leaf to canopy, since SLA $(x)$ makes the relevant parameters for the sunlit and shaded canopy functions of total $L$ (cf. de Pury and Farquhar 1997).

Results from our global simulations suggest that the combination of remedial updates to the canopy integration scheme and inclusion of the new treatment of $\operatorname{SLA}(x)$ significantly improves the representation of GPP in both the diagnostic and prognostic models. The generally good agreement in the geographic patterns of GPP in experiments D1 and P1 suggests that the additional degrees of freedom introduced by the prognostic canopy model do not lead to large divergence in canopy functional characteristics over most of the globe, compared to the observational constraints in the diagnostic model. Significant divergence is obvious in tundra regions.

First-order comparisons against global syntheses of observed NPP and $C_{\text {veg }}$ show potential underestimation of NPP for larch, arctic grass, and perhaps arctic shrub and temperate (C3) grasses. One likely explanation for these biases is the parameterization of the deciduous phenology model implemented in the prognostic carbon-nitrogen code. That model was developed and tested mainly for temperate climates, and even though there are mean temperature dependencies on several critical parameters (White et al. 1997) it is possible that these dependencies are not suitable for very cold climates.

The good agreement between prognostic model and observed ranges for NPP in forest vegetation types suggests that the canopy integration scheme performs well in the canopy types for which the $\operatorname{SLA}(x)$ relationship was established. Overestimation of $C_{\mathrm{veg}}$ for woody vegetation could be due to an underestimation of disturbance rates. The model includes a prognostic fire routine, but it has not yet been adequately evaluated and may underestimate rates of fire occurrence or fire intensity in woody vegetation. The nonfire mortality is currently prescribed as $0.5 \%$ year $^{-1}$ for all forest types, and this treatment may need to be modified to account for age-dependent changes in nonfire mortality. Another probable factor in the $C_{\mathrm{veg}}$ comparison is 
that the observations reflect modern forest carbon densities, which are influenced by harvest and other land management practices, while the prognostic model is being assessed at its long-term steady state in the absence of these anthropogenic disturbance factors. We also note that the difference between the two observation-based estimates of global total $C_{\text {veg }}$ is larger, by more than a factor of 2 , than the difference between the prognostic model estimate and the more recent of the two observation-based estimates, suggesting that our model estimate for global total $C_{\mathrm{veg}}$ may be within the range of uncertainty in the observations.

Global total NPP predicted by the model is about $30 \%$ lower than the mean of the observation-based estimates. The discrepancy can be framed in terms of differences in the formulation of the basic land cover types, differences in assumed area represented by individual vegetation types, and differences in predicted versus observed site-level NPP. The treatment of wetlands as nonvegetated in CLM certainly contributes to an underestimate in global total NPP. Underestimation of site-level NPP in the tundra is significant, with likely impact on albedo and temperature predictions when the prognostic model is coupled to an active atmospheric model in CCSM, but the influence of this bias on global total NPP is probably small due to the low observed productivity of tundra communities. Model underestimation of productivity in $\mathrm{C} 3$ nonarctic grasslands is a more likely contribution to low bias in global total NPP, due to the very large distribution of this vegetation type. Another possible factor is the difference in area estimated to be covered by tropical forest, which is $35 \%$ higher in the observation-based estimates than in the remote sensing-derived dataset used in CLM. Resolution of these differences will require a much more detailed evaluation of model predictions versus observations at multiple sites with high-quality carbon state and flux observations.

We have dealt here exclusively with the consequences of the CLM canopy integration scheme for carbon flux estimation, but there are also important consequences for water and energy fluxes (Wang and Leuning 1998; Dai et al. 2004). Another recent study examines the effects of our new canopy integration scheme, among other modifications, on latent heat flux and its partitioning into evaporation and transpiration in CLM in diagnostic canopy mode (Lawrence et al. 2007). That study shows that one consequence of the new canopy integration scheme is to shift the partitioning of total latent heat flux toward larger and more reasonable transpiration fraction. Other modifications to the soil hydrology scheme in that study reduce un- reasonable dry soil biases, leading to additional increases in global total GPP. It is possible that these hydrology modifications, once integrated with the prognostic carbon-nitrogen canopy model, will improve the model predictions of NPP in drought-prone ecosystems.

\section{Conclusions}

We have presented here a new theory for vertical canopy integration that provides a consistent basis for estimation of canopy leaf area index and canopy photosynthetic parameters in a prognostic canopy model, and that is also applicable to the estimation of photosynthetic parameters in a diagnostic model with leaf area index prescribed. We have shown through sensitivity tests and comparisons to observations that our proposed treatment of sunlit versus shaded canopy fraction combined with a linear form for $\operatorname{SLA}(x)$ is an improvement over the single-leaf model with constant SLA that is used in CLM3, and we have pointed out and corrected an additional logical flaw concerning the area basis for APAR in the single-leaf model for CLM3. Additional measurements are required to establish the variability of $\operatorname{SLA}(x)$ within and between PFTs, with measurements outside the temperate zone being a high priority.

Acknowledgments. We thank X. Zeng, G. Bonan, D. Schimel, and three anonymous reviewers for providing helpful comments on an earlier version of this manuscript. This work was supported in part by NASA Earth Science Enterprise, Terrestrial Ecology Program, Grant W19, 953 to P. E. Thornton. Additional support was provided by the National Center for Atmospheric Research (NCAR) through the NCAR Community Climate System Modeling program, and through the NCAR Biogeosciences program.

\section{APPENDIX}

\section{List of Abbreviations, and Variables and Associated Units}

APAR Absorbed photosynthetically active radiation

CCSM Community Climate System Model

CLM Community Land Model

PAR Photosynthetically active radiation

PFT Plant functional type

Rubisco Ribulose bis-phosphate carboxylase-oxygenase 
TABLE A1. List of variables and associated units.

\begin{tabular}{|c|c|c|}
\hline Variable & Units & Description \\
\hline$a_{R}$ & umol $\mathrm{CO}_{2} \mathrm{~g}_{\text {Rubisco }}{ }^{-1} \mathrm{~s}^{-1}$ & Specific activity of Rubisco \\
\hline$C_{\mathrm{CRa}}$ & $\mathrm{gC} \mathrm{m}^{-2} \mathrm{~s}^{-1}$ & Allocation flux to coarse roots \\
\hline$C_{\mathrm{FRa}}$ & $\mathrm{gC} \mathrm{m}^{-2} \mathrm{~s}^{-1}$ & Allocation flux to fine roots \\
\hline$C_{L}$ & $\mathrm{gC} \mathrm{m}^{-2}$ & Canopy leaf carbon pool \\
\hline$C_{\mathrm{La}}$ & $\mathrm{gC} \mathrm{m}^{-2} \mathrm{~s}^{-1}$ & Allocation flux to leaf \\
\hline$C_{\mathrm{S}}^{\mathrm{La}}$ & $\mathrm{gC} \mathrm{m} \mathrm{m}^{-2} \mathrm{~s}^{-1}$ & Allocation flux to stem \\
\hline$C_{\mathrm{veg}}$ & $\mathrm{kgC} \mathrm{m}^{-2}$ & Total vegetation carbon \\
\hline $\mathrm{CN}_{L}$ & 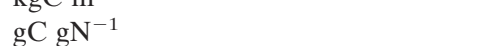 & Ratio of C:N in leaf \\
\hline$F_{\mathrm{LNR}}$ & proportion & Fraction of leaf nitrogen contained in Rubisco \\
\hline$F_{\mathrm{NR}}$ & $\mathrm{gN}$ in Rubisco/g Rubisco & Mass ratio of $\mathrm{N}$ in Rubisco \\
\hline$f_{\text {dir }}$ & proportion & Fraction of incoming PAR received as direct beam \\
\hline$f_{\text {sha }}$ & proportion & Shaded leaf area fraction at $x$ \\
\hline$f_{\text {sun }}$ & proportion & Sunlit leaf area fraction at $x$ \\
\hline$g$ & ${\mathrm{gC} \mathrm{gC}^{-1}}^{-1}$ & Growth respiration cost per unit newly allocated C \\
\hline GPP & $\mathrm{gC} \mathrm{m}^{-2} \mathrm{yr}^{-1}$ & Gross primary production \\
\hline$k_{b}$ & unitless & Canopy direct-beam extinction coefficient \\
\hline$L$ & $\mathrm{~m}^{2}$ one-sided leaf area $/ \mathrm{m}^{2}$ ground area & Canopy one-sided leaf area index \\
\hline$L_{\text {sha }}$ & $\mathrm{m}^{2}$ one-sided leaf area $/ \mathrm{m}^{2}$ ground area & Canopy shaded one-sided leaf area index \\
\hline$L_{\text {sun }}$ & $\mathrm{m}^{2}$ one-sided leaf area $/ \mathrm{m}^{2}$ ground area & Canopy sunlit one-sided leaf area index \\
\hline$m$ & $\mathrm{~m}^{2}$ ground area $\mathrm{gC}^{-1}$ & Linear slope coefficient for SLA $(x)$ \\
\hline$N_{a}$ & $\mathrm{gN} \mathrm{m}^{-2}$ & Area-based leaf nitrogen concentration \\
\hline NPP & $\mathrm{gC} \mathrm{m}^{-2} \mathrm{yr}^{-1}$ & Net primary production \\
\hline $\mathrm{PAR}_{C}$ & $\mathrm{~W} \mathrm{~m}^{-2}$ & PAR flux density per unit ground area \\
\hline $\mathrm{PAR}_{L}$ & $\mathrm{~W} \mathrm{~m} \mathrm{~m}^{-2}$ & PAR flux density per unit leaf area \\
\hline $\mathrm{PAR}_{0}$ & $\mathrm{~W} \mathrm{~m} \mathrm{~m}^{-2}$ & PAR at noon \\
\hline$R_{m}$ & $\mathrm{gC} \mathrm{m}^{-2} \mathrm{~s}^{-1}$ & Maintenance respiration \\
\hline SLA & $\mathrm{m}^{2}$ one-sided leaf area $\mathrm{gC}^{-1}$ & Specific leaf area \\
\hline $\mathrm{SLA}_{0}$ & $\mathrm{~m}^{2}$ one-sided leaf area $\mathrm{gC}^{-1}$ & Specific leaf area at $x=0$ \\
\hline$V_{\text {cmax }}$ & umol $\mathrm{CO}_{2} \mathrm{~m}^{-2} \mathrm{~s}^{-1}$ & Leaf-scale maximum carboxylation rate, $25^{\circ} \mathrm{C}$ \\
\hline$x$ & $\mathrm{~m}^{2}$ one-sided leaf area $/ \mathrm{m}^{2}$ ground area & Overlying one-sided leaf area index \\
\hline
\end{tabular}

\section{REFERENCES}

Atjay, G. L., P. Ketner, and P. Duvigneaud, 1979: Terrestrial primary production and phytomass. The Global Carbon Cycle, B. Bolin et al., Eds., John Wiley \& Sons, 129-181.

Berthelot, M., P. Friedlingstein, P. Ciais, P. Monfray, J. L. Dufresne, H. Le Treut, and L. Fairhead, 2002: Global response of the terrestrial biosphere to $\mathrm{CO}_{2}$ and climate change using a coupled climate-carbon cycle model. Global Biogeochem. Cycles, 16, 1084, doi:10.1029/2001GB001827.

Betts, R. A., P. M. Cox, S. E. Lee, and F. I. Woodward, 1997: Contrasting physiological and structural vegetation feedbacks in climate change simulations. Nature, 387, 796-799.

Bonan, G. B., 1998: The land surface climatology for the NCAR land surface model coupled to the NCAR Community Climate Model. J. Climate, 11, 1307-1326.

Bond, B. J., B. T. Farnsworth, R. A. Coulombe, and W. E. Winner, 1999: Foliage physiology and biochemistry in response to light gradients in conifers with varying shade tolerance. Oecologia, 120, 183-192.

Boone, A., and Coauthors, 2004: The Rhône-Aggregation Land Surface Scheme intercomparison project: An overview. $J$. Climate, 17, 187-208.

Carswell, F. E., and Coauthors, 2000: Photosynthetic capacity in a central Amazonian rain forest. Tree Physiol., 20, 179-186.

Collins, W. D., and Coauthors, 2006: The Community Climate System Model version 3 (CCSM3). J. Climate, 19, 2122-2143.
Cox, P. M., R. A. Betts, C. B. Bunton, R. L. H. Essery, P. R. Rowntree, and J. Smith, 1999: The impact of new land surface physics on the GCM simulation of climate and climate sensitivity. Climate Dyn., 15, 183-203.

,-- C. D. Jones, S. A. Spall, and I. J. Totterdell, 2000: Acceleration of global warming due to carbon-cycle feedbacks in a coupled climate model. Nature, 408, 184-187.

Cramer, J., T. Fahey, and J. Battles, 2000: Patterns of leaf mass, area, and nitrogen in young northern hardwood forests. Amer. Midland Nat., 144, 253-264.

Dai, Y., R. E. Dickinson, and Y.-P. Wang, 2004: A two-big-leaf model for canopy temperature, photosynthesis, and stomatal conductance. J. Climate, 17, 2281-2299.

Dang, Q. L., H. A. Margolis, M. Sy, M. R. Coyea, G. J. Collatz, and C. L. Walthall, 1997: Profiles of photosynthetically active radiation, nitrogen and photosynthetic capacity in the boreal forest: Implications for scaling from leaf to canopy. J. Geophys. Res., 102, 28 845-28 859.

Delire, C., J. A. Foley, and S. Thompson, 2004: Long-term variability in a coupled atmosphere-biosphere model. J. Climate, 17, 3947-3959.

Delworth, T. L., R. J. Stouffer, K. W. Dixon, M. J. Spelman, T. R. Knutson, A. J. Broccoli, P. J. Kushner, and R. T. Wetherald, 2002: Review of simulations of climate variability and change with the GFDL R30 coupled climate model. Climate Dyn., 19, 555-574.

de Pury, D. G. G., and G. D. Farquhar, 1997: Simple scaling of 
photosynthesis from leaves to canopies without the errors of big-leaf models. Plant Cell Environ., 20, 537-557.

Dewar, R. C., 1996: The correlation between plant growth and intercepted radiation: An interpretation in terms of optimal plant nitrogen content. Ann. Bot., 78, 125-136.

Dickinson, R. E., 1984: Modeling evapotranspiration for threedimensional global climate models. Climate Processes and Climate Sensitivity, Geophys. Monogr., Vol. 29, Amer. Geophys. Union, 58-72.

—- M. Shaikh, R. Bryant, and L. Graumlich, 1998: Interactive canopies for a climate model. J. Climate, 11, 2823-2836.

_ - and Coauthors, 2002: Nitrogen controls on climate model evapotranspiration. J. Climate, 15, 278-295.

_ , K. W. Oleson, G. B. Bonan, F. M. Hoffman, P. Thornton, M. Vertenstein, Z.-L. Yang, and X. Zeng, 2006: The Community Land Model and its climate statistics as a component of the Community Climate System Model. J. Climate, 19, 2302-2324.

Dixon, R. K., S. Brown, R. A. Houghton, A. M. Solomon, M. C. Trexler, and J. Wisniewski, 1994: Carbon pools and flux of global forest ecosystems. Science, 263, 185-190.

Ducoudré, N. I., K. Laval, and A. Perrier, 1993: SECHIBA, a new set of parameterizations of the hydrologic exchanges at the land-atmosphere interface within the LMD atmospheric general circulation model. J. Climate, 6, 248-273.

Dufresne, J.-L., P. Friedlingstein, M. Berthelot, L. Bopp, P. Ciais, L. Fairhead, H. Le Treut, and P. Monfray, 2002: On the magnitude of positive feedback between future climate change and the carbon cycle. Geophys. Res. Lett., 29, 1405, doi:10.1029/2001GL013777.

Evans, J. R., and H. Poorter, 2001: Photosynthetic acclimation of plants to growth irradiance: The relative importance of specific leaf area and nitrogen partitioning in maximizing carbon gain. Plant Cell Environ., 24, 755-767.

Farquhar, G. D., and S. von Caemmerer, 1982: Modelling of photosynthetic response to environmental conditions. Water Relation and Carbon Assimilation, O. L. Lange et al., Eds., Vol. 2, Physiological Plant Ecology, Springer-Verlag, 549-587.

$\longrightarrow,-$, and J. A. Berry, 1980: A biochemical model of photosynthetic $\mathrm{CO}_{2}$ assimilation in leaves of $\mathrm{C}_{3}$ species. Planta, 149, 78-90.

Field, C., 1983: Allocating leaf nitrogen for the maximization of carbon gain: Leaf age as a control on the allocation program. Oecologia, 56, 341-347.

— J. Jerino, and H. A. Mooney, 1983: Compromises between water-use efficiency and nitrogen-use efficiency in five species of California evergreens. Oecologia, 60, 384-389.

Friedl, M. A., J. Michaelsen, F. W. Davis, H. Walker, and D. S. Schimel, 1994: Estimating grassland biomass and leaf area index using ground and satellite data. Int. J. Remote Sens., 15, 1401-1420.

Friedlingstein, P., L. Bopp, P. Ciais, J.-L. Dufresne, L. Fairhead, H. LeTreut, P. Monfray, and J. Orr, 2001: Positive feedback between future climate change and the carbon cycle. Geophys. Res. Lett., 28, 1543-1546.

Gutschick, V. P., and F. W. Wiegel, 1988: Optimizing the canopy photosynthesis rate by patterns of investment in specific leaf mass. Amer. Nat., 132, 67-86.

Han, Q., T. Kawasaki, S. Katahata, Y. Mukai, and Y. Chiba, 2003: Horizontal and vertical variations in photosynthetic capacity in a Pinus densiflora crown in relation to leaf nitrogen allo- cation and acclimation to irradiance. Tree Physiol., 23, 851857

Hikosaka, K., I. Terashima, and S. Katoh, 1994: Effects of leaf age, nitrogen nutrition and photon flux density on the distribution of nitrogen among leaves of a vine (lpomoea tricolor Cav.) grown horizontally to avoid mutual shading of leaves. Oecologia, 97, 451-457.

Hirose, T., and M. J. A. Werger, 1994: Photosynthetic capacity and nitrogen partitioning among species in the canopy of a herbaceous plant community. Oecologia, 100, 203-212.

Hollinger, D. Y., 1996: Optimality and nitrogen allocation in a tree canopy. Tree Physiol., 16, 627-634.

Houghton, J. T., Y. Ding, D. J. Griggs, M. Noguer, P. J. van der Linden, X. Dai, K. Maskell, and C. A. Johnson, Eds., 2001: Climate Change 2001: The Scientific Basis. Cambridge University Press, $881 \mathrm{pp}$.

Ishida, A., T. Toma, and Marjenah, 1999: Leaf gas exchange and chlorophyll flourescence in relation to leaf angle, azimuth, and canopy position in the tropical pioneer tree, Macaranga conifera. Tree Physiol., 19, 117-124.

Johns, T. C., R. E. Carnell, J. F. Crossley, J. M. Gregory, J. F. B. Mitchell, C. A. Senior, S. F. B. Tett, and R. A. Wood, 1997: The second Hadley Centre coupled ocean-atmosphere GCM: Model description, spinup, and validation. Climate Dyn., 13, 103-134.

Kalnay, E., and Coauthors, 1996: The NCEP/NCAR 40-Year Reanalysis Project. Bull. Amer. Meteor. Soc., 77, 437-471.

Knops, J. M. H., and K. Reinhart, 2000: Specific leaf area along a nitrogen fertilization gradient. Amer. Midland Nat., 144, 265 272.

Kuehn, G. D., and B. A. McFadden, 1969: Ribulose 1, 5-diphosphate carboxylase from Hydrogenomonas eutropha and $\mathrm{Hy}$ drogenomonas facilis. II. Molecular weight, subunits, composition, and sulfhydryl groups. Biochem. J., 8, 2403-2408.

Kumagai, T., and Coauthors, 2006: Modeling $\mathrm{CO}_{2}$ exchange over a Bornean tropical rain forest using measured vertical and horizontal variations in leaf-level physiological parameters and leaf area densities. J. Geophys. Res., 111, D10107, doi:10.1029/2005JD006676.

Lawrence, D. M., P. E. Thornton, K. W. Oleson, and G. B. Bonan, 2007: The partitioning of evapotranspiration into transpiration, soil evaporation, and canopy evaporation in a GCM: Impacts on land-atmosphere interaction. J. Hydrometeor., in press.

Le Roux, X., H. SinoQuet, and M. Vandame, 1999: Spatial distribution of leaf dry weight per area and leaf nitrogen concentration in relation to local radiation regime within an isolated tree crown. Tree Physiol., 19, 181-188.

Levis, S., J. A. Foley, and D. Pollard, 2000: Large-scale vegetation feedbacks on a doubled $\mathrm{CO}_{2}$ climate. J. Climate, 13, 1313 1325.

Mahfouf, J.-F., A. O. Manzi, J. Noilhan, H. Giordani, and M. Déqué, 1995: The land surface scheme ISBA within the Météo-France climate model ARPEGE. Part I: Implementation and preliminary results. J. Climate, 8, 2039-2057.

Medlyn, B. E., 1996: The optimal allocation of nitrogen within the $\mathrm{C}_{3}$ photosynthetic system at elevated $\mathrm{CO}_{2}$. Aust. J. Plant Physiol., 23, 593-603.

Meir, P., B. Kruijt, M. Braodmeadow, E. Barbosa, O. Kull, F. Carswell, A. Nobre, and P. G. Jarvis, 2002: Acclimation of photosynthetic capacity to irradiance in tree canopies in re- 
lation to leaf nitrogen concentration and leaf mass per unit area. Plant Cell Environ., 25, 343-357.

Meziane, D., and B. Shipley, 1999: Interacting determinants of specific leaf area in 22 herbaceous species: Effects of irradiance and nutrient availability. Plant Cell Environ., 22, 447459.

Monserud, R. A., and J. D. Marshall, 1999: Allometric crown relations in three northern Idaho conifer species. Can. J. For. Res., 29, 521-535.

Niinemets, Ü., and J. D. Tenhunen, 1997: A model separating leaf structural and physiological effects on carbon gain along light gradients for the shade-tolerant species Acer saccharum. Plant Cell Environ., 20, 845-866.

_ , and O. Kull, 1998: Stoichiometry of foliar carbon constituents varies along light gradients in temperate woody canopies: Implications for foliage morphological plasticity. Tree Physiol., 18, 467-479.

— — - a and J. D. Tenhunen, 1998: An analysis of light effects on foliar morphology, physiology, and light interception in temperate deciduous woody species of contrasting shade tolerance. Tree Physiol., 18, 681-696.

— D. D. Ellsworth, A. Lukjanova, and M. Tobias, 2002: Dependence of needle architecture and chemical composition on canopy light availability in three North American Pinus species with contrasting needle length. Tree Physiol., 22, 747 761.

Norman, J. M., 1980: Interfacing leaf and canopy irradiance interception models. Predicting Photosynthesis for Ecosystem Models, J. D. Hesketh and J. W. Jones, Eds., CRC Press, Inc., 49-67.

Oleson, K. W., and Coauthors, 2004: Technical description of the Community Land Model (CLM). National Center for Atmospheric Research Tech. Note NCARTN-461+STR, 174 pp.

Poorter, H., and J. R. Evans, 1998: Photosynthetic nitrogen-use efficiency of species that differ inherently in specific leaf area. Oecologia, 116, 26-37.

Poorter, L., S. F. Oberbauer, and D. B. Clark, 1995: Leaf optical properties along a vertical gradient in a tropical rain forest canopy in Costa Rica. Amer. J. Bot., 82, 1257-1263.

Raulier, F., P. Y. Bernier, and C.-H. Ung, 1999: Canopy photosynthesis of sugar maple (Acer saccharum): Comparing bigleaf and multilayer extrapolations of leaf-level measurements. Tree Physiol., 19, 407-420.

Reich, P. B., B. D. Kloeppel, D. S. Ellsworth, and M. B. Walters, 1995: Different photosynthesis-nitrogen relations in deciduous hardwood and evergreen coniferous tree species. Oecologia, 104, 24-30.

—, D. S. Ellsworth, and M. B. Walters, 1998: Leaf structure (specific leaf area) modulates photosynthesis-nitrogen relations: Evidence from within and across species and functional groups. Funct. Ecol., 12, 948-958.

Reynolds, J. F., J. Chen, P. C. Harley, D. W. Hilbert, R. L. Dougherty, and J. D. Tenhunen, 1992: Modeling the effects of elevated $\mathrm{CO}_{2}$ on plants: Extrapolating leaf response to a canopy. Agric. For. Meteor., 61, 69-94.

Roberts, J., R. Hopkins, and M. Morecroft, 1999: Towards a predictive description of forest canopies from litter properties. Funct. Ecol., 13, 265-272.

Rosati, A., G. Esparza, T. M. DeJong, and R. W. Pearcy, 1999: Influence of canopy light environment and nitrogen availability on leaf photosynthetic characteristics and photosynthetic nitrogen-use efficiency of field-grown nectarine trees. Tree Physiol., 19, 173-180.

_, K. R. Day, and T. M. DeJong, 2000: Distribution of leaf mass per unit area and leaf nitrogen concentration determine partitioning of leaf nitrogen within tree canopies. Tree Physiol., 20, 271-276.

Roy, J., B. Saugier, and H. A. Mooney, Eds., 2001: Terrestrial Global Productivity. Academic Press, 573 pp.

Scholes, R. J., P. G. H. Frost, and Y. H. Tian, 2004: Canopy structure in savannas along a moisture gradient on Kalahari sands. Global Change Biol., 10, 292-302.

Sellers, P. J., Y. Mintz, Y. C. Sud, and A. Dalcher, 1986: A simple biosphere model $(\mathrm{SiB})$ for use within general circulation models. J. Atmos. Sci., 43, 505-531.

_ J. A. Berry, G. J. Collatz, C. B. Field, and F. G. Hall, 1992: Canopy reflectance, photosynthesis, and transpiration. III. A reanalysis using improved leaf models and a new canopy integration scheme. Remote Sens. Environ., 42, 187-216.

Sims, D. A., and R. W. Pearcy, 1989: Photosynthesis characteristics of a tropical forest understory herb, Alocasia macrorrhiza, and a related crop species, Colocasia esculenta grown in contrasting light environments. Oecologia, 79, 53-59.

Sinclair, T. R., C. E. Murphy, and K. R. Knoerr, 1976: Development and evaluation of simplified models for simulating canopy photosynthesis and transpiration. J. Appl. Ecol., 13, 813-829.

Souza, R. P., and I. F. M. Válio, 2003: Leaf optical properties as affected by shade in saplings of six tropical tree species differing in successional status. Brazilian J. Plant Physiol., 15, $49-54$.

Stockle, C. O., 1992: Canopy photosynthesis and transpiration estimates using radiation interception models with different levels of detail. Ecol. Modell., 60, 31-44.

Thornton, P. E., 1998: Regional ecosystem simulation: Combining surface- and satellite-based observations to study linkages between terrestrial energy and mass budgets. Ph.D. thesis, University of Montana, $280 \mathrm{pp}$.

, and N. A. Rosenbloom, 2005: Ecosystem model spin-up: Estimating steady state conditions in a coupled terrestrial carbon and nitrogen cycle model. Ecol. Modell., 189, 25-48. , and Coauthors, 2002: Modeling and measuring the effects of disturbance history and climate on carbon and water budgets in evergreen needleleaf forests. Agric. For. Meteor., 113, 185 222.

Wang, Y.-P., and R. Leuning, 1998: A two-leaf model for canopy conductance, photosynthesis and partitioning of available energy I: Model description and comparison with a multilayered model. Agric. For. Meteor., 91, 89-111.

WBGU, 1988: Die Anrechnung biolischer Quellen und Senken in Kyoto-Protokoll: Fortschritt oder Rückschlang für den globalen Umweltschutz Sondergutachten (in German). Wissenschaftlicher Beirat der Bundesregierung Globale Umweltveränerungen, Bremerhaven, Germany, $76 \mathrm{pp}$.

White, J. D., and N. A. Scott, 2006: Specific leaf area and nitrogen distribution in New Zealand forests: Species independently respond to intercepted light. For. Ecol. Manage., 226, 319329 .

White, M. A., P. E. Thornton, and S. W. Running, 1997: A continental phenology model for monitoring vegetation responses to interannual climatic variability. Global Biogeochem. Cycles, 11, 217-234.

,,--- , and R. R. Nemani, 2000: Parameterization and 
sensitivity analysis of the BIOME-BGC terrestrial ecosystem model: Net primary production controls. Earth Interactions, 4. [Available online at http://EarthInteractions.org.]

Wilson, K. B., D. B. Baldocchi, and P. J. Hanson, 2000: Spatial and seasonal variability of photosynthetic parameters and their relationship to leaf nitrogen in a deciduous forest. Tree Physiol., 20, 565-578.

Woodrow, I. E., and J. A. Berry, 1988: Enzymatic regulation of photosynthetic $\mathrm{CO}_{2}$ fixation in $\mathrm{C}_{3}$ plants. Annu. Rev. Plant Physiol. Plant Mol. Biol., 39, 533-594.

Wullschleger, S. D., 1993: Biochemical limitations to carbon assimilation in $\mathrm{C}_{3}$ plants- $\mathrm{A}$ retrospective analysis of the $\mathrm{A} / \mathrm{C}_{\mathrm{i}}$ curves from 109 species. J. Exp. Bot., 44, 907-920.

Xue, Y., P. J. Sellers, J. L. Kinter, and J. Shukla, 1991: A simplified biosphere model for global climate studies. J. Climate, $\mathbf{4}$, 345-364. 